\title{
Primer anarquismo español y cultura obrera (1868-1910). El peso de la subordinación a la defensa de la identidad obrera.
}

\section{Michel Ralle*}

Resumo: As interpretações particulares dos grandes temas libertários por parte dos antiautoritários espanhóis se apoiaram nas elaborações sociais e discursivas dos coletivos operários. Iniciativas de organização e modelos de defesa levaram a verdadeiras construções ideológicas que deram um caráter totalmente operário às propostas habituais do anarquismo bakuninista. Tanto a exaltação da organização concebida como fim em si mesmo como a reticência em propor a greve geral foram duradouras. O objetivo essencial continuou sendo a defesa prioritária da identidade operária e de suas formas de presença social. Até nos grandes conflitos dos primeiros anos do século XX são visíveis as tensões entre estas interpretações e a visão libertária de mudança social, mais ideológica e mais radical.

Palavras chave: anarquismo espanhol, cultura operária, greve geral.

Resumen: Las interpretaciones particulares de los grandes temas libertarios por los antiautoritarios españoles se apoyaron en las elaboraciones sociales y discursivas de los colectivos obreros. Iniciativas de organización y modelos de defensa llevaron a unas verdaderas construcciones ideológicas que dieron una tonalidad totalmente obrerista a las propuestas habituales del anarquismo bakuninista. Fueron duraderas tanto la exaltación de la organización concebida como fin en sí mismo como la reticencia a proponer la huelga general. El objetivo esencial siguió siendo la defensa prioritaria de la identidad obrera y de sus formas de presencia social. Hasta en los grandes conflictos de los primeros años del siglo XX son visibles las tensiones con la visión libertaria, más ideológica y más radical, del cambio social.

Palabras clave: anarquismo español, cultura obrera, huelga general.

Atribuir un papel significativo a la cultura política obrera en la elaboración del primer anarquismo español es bastante menos frecuente que considerarlo como una consecuencia de la situación sociopolítica de los sectores populares. Una gran parte de la historiografía suele explicar la excepcional presencia de la corriente libertaria durante bastante más que la mitad de un siglo - entre 1870 y el fin, en 1939, de la guerra civil ${ }^{1}$ - por un contexto histórico en el que se combinarían el

* Professor da Université de Paris IV (Sorbonne).

1 Por supuesto, en las condiciones de la represión franquista, el anarquismo continuó a tener presencia hasta principios de los años 1950, al menos. 
retraso del desarrollo industrial y el desfase de las clases populares con respecto a los intentos de establecer un régimen representativo y una forma estatal similares a los de los grandes paises de Europa. El cambio económico posterior a la crisis de la monarquía absoluta de Fernando VII (1814-1833) proporciona un primer nivel de explicaciones. En España el proceso industrializadorfue tardío y su impacto desigual en las distintas partes del territorio. Los colectivos obreros globalmente afectados pero empleados a menudo en formas trabajo de tipo semiindustrial o artesanal, se hubieran reconocido en la defensa de la autonomía individual y colectiva propia de los proyectos ácratas. Pero sólo con determinantes de orden económico difícilmente se explicaría que en Cataluña, único conjunto industrializado antes de los años 1880, se dieran a la vez actitudes reformistas, las de una precoz federación de los obreros del textil, las llamadas "Tres Clases de Vapor », y una influencia libertaria en sectores significativos del trabajo, entre ellos los oficios. De hecho, las interpretaciones recurren a menudo a la historia política subrayando en particular el papel posible del tipo de republicanismo que se formó en España, con un peso importante de la variante federal, y, a veces, el del antiestatismo de las capas populares. Ambos serían significativos tanto de las dificultades para construir un estado de apariencias liberales como de la poca capacidad de integración de los componentes de orden democrático, los cuales, a pesar del desgaste de la forma monárquica autoritaria -cae Isabel II con la « revolución » de septiembre de 1868-, fueron perdiendo, de modo algo paradójico, parte de su poder de convicción en la opinión popular urbana. Agotados, durante los años 1868-1872, los intentos de establecer una forma monárquica representativa, una breve república, proclamada en febrero de 1873, no consiguió evitar, unos meses después, el regreso, por la vía de un pronunciamiento militar, de un tipo de monarquía que, igual que la de Isabel II, eludía gran parte de los mecanismos de representación que formalmente admitía ${ }^{2}$. No es la intención del presente estudio proponer una interpretación de las causas generales del éxito del anarquismo en España -se aludirá desde luego a algunassino subrayar que la cultura sociopolítica de los colectivos obreros contribuyó mucho más de lo que se suele atribuirle en la elaboración de las primeras formas del proyecto anarquista. Al contrario de lo que sostienen muchas evocaciones de la corriente libertaria durante el « sexenio democrático »(1868-1874)3 , no fueron ni sencillas ni pasajeras.

Igual que en otros paises la primera elaboración anarquista que se conoció en España fue la bakuninista. Se debió a los tan mencionados primeros contactos, después de septiembre de 1868 , con unos núcleos obreros activos y preocupados por hacerse socialmente más visibles mientras rompían con los republicanismos ${ }^{4}$. Planteando la « emancipación social » a través de un choque revolucionario la lógica del bakuninismo, tal como se percibía, parecía prolongar los temas del republicanismo federal entre aquellos obreros que ahora se apartaban de una vía en la que los cambios sólo afectarían las instituciones políticas. En un contexto en el que se exaltaba la virtud de la « asociación », una federación española de

2 El marco político definitivo lo fija en la constitución de 1876 el político conservador Antonio Cánovas.

3 La historiografía y la memoria histórica suelen usar la expresión para llamar el periodo comprendido entre la caida de Isabel II, en septiembre de 1868, y el golpe de estado del general Pavía, en enero de 1874, el cual señala el inicio del proceso « restaurador».

4 El trabajo más preciso sobre los contactos con el bakuninista italiano Fanelli en la obra de M. Nettlau editada por R. Lamberet, La Première Internationale en Espagne (1868-1886), Dordrecht, D. Reidel Publishing Company, 1969. Importante también el libro pionero de MARTí, Cassimir. Orígenes del anarquismo en España, Barcelona : editorial Teide, 1959. Se citan en el artículo el libro de memorias de LORENZO, Anselmo. El proletariado militante, reed. por J. Álvarez Junco. Bilbao: ed. ZYX, 1974, y la síntesis de TERMES, J. Anarquismo y sindicalismo en España. La Primera Internacional (1864-1881). Barcelona: ed. Ariel, 1972. 
la Asociación internacional de trabajadores (AIT), la «Primera Internacional », vino a añadir a la función de defensa económica de las secciones que la formaron la posibilidad de difundir la temática de la « revolución social ». Constituida en el « primer congreso obrero », en la Barcelona de junio 1870, la « federación regional española » (FRE) de la AIT hizo mucho mayor y definitiva la distancia entre los colectivos obreros militantes y los objetivos políticos de las distintas variantes republicanas 5 .

\section{La Federación española de la Primera internacional : una recepción matizada del bakuninismo}

Es lógica la insistencia de muchos estudios en la importancia de la temática ideológica de la corriente republicana para explicar la recepción del bakuninismo en España. Su variante federal había heredado parte del antiestatismo de Proudhon -Pi y Margall, el dirigente más conocido, había sido su principal traductor ${ }^{6}$. Pero la debilidad sociopolíotica de los republicanos dejaba insatisfechos a los colectivos obreros que también esperaban efectos sociales de un cambio político7. Su dificultad para dibujar unos perspectivas sociales en un momento de mayor actividad obrera contribuyó a su desapego y a la receptividad de unos cuantos, más radicales, al tema de la revolución social. En lo que esa vino a significar parecen haber sido fundamentales las formas de la inserción social de la sensibilidad libertaria. En la perspectiva bakuninista los medios obreros podían constituir una base social decisiva en su objetivo de separación con lo político. Era lógico además que los primeros núcleos anarquizantes percibieran el interés de los modelos de presencia propios de las prácticas de defensa de los colectivos asalariados -se habían venido elaborando desde una década. Son muy perceptibles en las propuestas de organización y de acción de la FRE. Éstas, además de favorecer la separación radical con lo " político », orientaron el proyecto bakuninista en un sentido obrerista que tendió a modificarlo. Integradas por la federación, la cual se inscribía, al menos de manera implícita, en la perspectiva global de una revolución social, le dieron una visibilidad sociopolítica particular.

Es notable que el congreso, además de rechazar la " participación política », también aprobara, después de un largo debate, unas modalidades precisas de " defensa económica ${ }^{8}$. No fueron sólo un intento, frustrado como lo veremos, de aproximar la actividad de tipo sindical de la FRE a lo que creía ser el proyecto bakuninista. En la combinación entre defensa social y objetivos políticos revolucionarios, el elemento central del modelo de organización de la FRE fue una huelga basada en la constitución de " cajas de resistencia ", las cuales habían de depender de una caja central cuyo papel consistiría en favorecer o en templar las huelgas para poder dirigirlas en un momento oportuno, aunque lejano, hacia el enfrentamiento decisivo capaz de provocar la frecuentemente invocada " liquidación social ». Aunque el bakuninismo no parecía haber sido dejado de lado, las iniciativas de huelgas de las seccionnes se encontraron subordinadas a la cuestión de las reservas financieras de la federación la cual construyó un

5 Regional » para « española » o « nacional » remite a la presencia de la temática bakuninista

6 Lista de las traducciones de Pi y Margall entre 1869 y 1972 en JUNCO, José Álvarez., La ideología política del anarquismo español (1868-1910). Madrid: ed. Siglo XXI, 1976, p. 363.

7 El pasaje del federalismo al bakuninismo en ARRANZ, Luiz; ELORZA, Antonio. trabajadores: la definición bakuninista de la clase obrera madrileña ». En: Revista de Trabajo. Madrid, n 52, p 353-452.

8 Los debates en la edición de las actas del congreso de ABERLOA, V. M. I congreso obrero español, Madrid: ed. ZYX, 1972, p. 134-198. 
discurso justificativo para no declarar reglamentarios la mayoría de los intentos de las secciones de llevar conflictos de trabajo. Insistía en la prioridad de proteger la organización del riesgo de desaparecer por falta de fondos -la capacidad de acumularlos constituía una de las señales de su legitimidad. En la medida en que las instancias dirigentes aplicaron de modo cada vez más nítido el modelo hasta el punto de ver con la mayor desconfianza el aumento de las movilizaciones sociales, la línea de la FRE tendió a ser antagónica con los llamamientos bakuninistas a que los conflictos puntuales se transformaran en decisivos.

Muchos trabajos consideran que el modelo de huelga de la FRE sólo fue ocasional y pasajero. Mencionan poco la continuidad de los esfuerzos de la federación para disuadir a la gran mayoría de los huelguistas concretos que le pidieron ayuda en 1872 y 1873 , años de claro auge de los conflictos 9 . Pero el modelo de acción con caja de resistencia no fue efímero. Entre los sectores obreros que se reconocían en la sensibilidad libertaria, volvió a asomar en 1881 bajo la forma de una nueva federación, la de « trabajadores de la región española » (FTRE), la cual, constituida en el contexto de la primera apertura de la monarquía instalada en 1875, intentó reproducír los modelos de organización y de acción de la FRE a pesar de su incapacidad anterior para regular las huelgas de las secciones afiliadas ${ }^{10}$.

La trayectoria de la FRE no tiene, por consiguiente, la linearidad que muchos le suelen atribuir. Incluso si las apariencias no muestran tensiones internas. No aparecen como tales en los periódicos identificados a la federación y que la acompañan en las más importantes ciudades del país, manifestación sin precedente de una expresión propia de los sectores obreros. Los redactan en parte los militantes interesados por los aspectos globales de la « revolución social ». Ellos son, en general, los que han tenido una relación directa con la perspectiva de ruptura bakuninista -es un núcleo activo pero muy numerosos. También escriben obreros vinculados con las actividades de defensa concreta del trabajo sobre las que informan subrayando la actividad de organización -a pesar de menos estudiado este otro gran tema de la prensa « internacionalista » cubre más espacio. Tampoco los documentos internos de la FRE señalan conflictos abiertos entre dos orientaciones durante sus casi cuatro años de vida pública. El que el modelo de huelga elaborado subordinara la acción a los supuestos intereses de la federación, con un claro desfase con respecto al recurso a la capacidad de indignación, exaltado por el discurso bakuninista"1, muestra que se ha ido constituyendo una dinámica dominantemente obrera. La señala el empleo, más que de otras, de la palabra « antiautoritario » cuando los miembros y las instancias de la FRE quieren autodefinirse ${ }^{12}$. En una federación de defensa las alusiones a la identidad anarquista tenían que ser algo implícitas. El que el uso durara muestra que la palabra remite a una percepción particular y propia de la vida de la FRE. Se empleará en este texto para tomar en cuenta el papel de ese segundo componente, menos señalado por los estudios aunque más numeroso dentro de la federación.

En todo caso, puede hasta sorprender la prudencia de aquellos militantes que parecen más cercanos a los esquemas bakuninistas. Bastante presentes en

9 Un testimonio nítido en la abundante correspondencia conservada en la biblioteca Arús de Barcelona, de hecho las copias de las cartas mandadas a las secciones. Edición por SERRANO, Carlos Seco; .SAS, Maria Tereza Mártinez de. Cartas, comunicaciones y circulares del Consejo Federal y de la Comisión Federal de la Región Española. Barcelona: ed. Universidad de Barcelona, 7 v., 1972-1987.

10 Lo demuestran las cartas a las secciones que pedían ayudas para sostener huelgas (Idem, sobre todo v. IV a VII)).

11 Cf. : JUNCO, José Álvarez. Op. cit., p. 381-388.

12 Ya se emplea la palabra en 1870 (BATTANER, M. Paz. Vocabulario político social en España. Anejos del boletín de la Real Academia española, Anejo n. XXXVII, Madrid, 1877, p. 285) 
la realización de los periódicos ${ }^{13}$, y con unos escritos de tonalidad radical cuando se trata de denunciar la injusticia social o de insistir en el necesario cambio de sociedad, sólo en algunas ocasiones señalan que el modelo de huelgas de la FRE la está llevando a desprenderse de la capacidad de la cólera trabajadora tan necesaria para la revolución social ${ }^{14}$. Para que esta modalidad aparezca como componente de la acción habrá que esperar al menos hasta le segunda mitad de los años 1880 -entonces ya no existía prácticamente presencia organizada bajo las siglas FTRE. Sólo más tarde, todavía, aparecieron críticas más directas a la orientación de la FRE. Anselmo Lorenzo, una de las más conocidas personalidades del anarquismo español, las expuso en 1901 en el libro de « memorias » ya mencionado ${ }^{15}$. Se publicó en un momento en el que la combatividad obrera alcanzaba un nivel inédito y algunos sectores libertarios llamaban a realizar huelgas generales -ya se habían convertido en tema central de los debates del sindicalismo revolucionario francés ${ }^{16}$. Si A. Lorenzo señala que la distancia entre el modelo y la acción redujo la FRE a la impotencia en materia de acción, lo ve como algo pasajero y casi olvidado -fue recibido por la historiografía como una incitación a no conceder gran importancia a las modalidades de defensa de la FRE y a su constancia ${ }^{17}$. No fueron, sin embargo, unas iniciativas pragmáticas pronto borradas por las temáticas más claramente anarquistas -de hecho cuando se debilitaron no las sustituyeron un modelo claro de movilización. De hecho, el meyor interés de la corriente libertaria española por la huelga general a partir de 1890 se debió a un estímulo externo : permitía distinguirse de la forma de Primero de mayo introducida por los partidos obreros de la corriente marxista. Además tardaría todavía algunos años en cuajar. Incluso cuando, a principios del nuevo siglo, pareció imponerse con la multiplicación de los llamamientos a generalizar las huelgas, éstos no contradecían siempre una visión más sindical de la acción - se evocará esa fase en la última parte de este estudio.

No parece posible aislar el modelo de huelga establecido, ya desde 1870 , por la FRE de lo que suponían las prácticas de la organización y los discursos que las justificaban. Los textos la exaltan como medio de garantizar la construcción de un espacio puramente obrero, alternativa total a lo político -y a lo que esto lleva consigo (desde la imagen del poder hasta las modelos culturales). El modelo organizativo no desempeñó, por consiguiente, un papel sólo funcional. Desde el principio la forma con la que se le entendía constituyó una alternativa a las propuestas republicanas que se habían difundido en los ámbitos urbanos. Lo fue también después frente a aquella orientación, la marxista, que proponía que la clase constituyera un partido político propio. En los años 1870-1880 no constituía un rival peligroso, -el núcleo del futuro partido socialista se había formado desde la estancia en España, en 1871-1872, de Paul Lafargue, cuando, aprovechándose del pasaporte español que le daba su origen cubano, estaba huyendo de la represión desencadenada después de la Commune de París. Aunque no se va a evocar aquí, el itinerario, también particular, del socialismo español tampoco se libró de la cultura política obrera que se quiere evocar aquí.

La defensa aferrada de un tipo de huelga llevada a partir de cajas de resistencia de las que se esperaba que un día se convertirían en medios potentes capaces

13 La Emancipación, de Madrid, es el único que se convierte durante sus últimos meses, entre mediados de 1872 y abril de 1873, en órgano del grupo que defiende al Consejo General después de la participación de algunos militantes en un grupo dirigido por un yerno de Marx, P. Lafargue y venido a España para huir de la represión de la Commune.

14 “Cartas a los trabajadores del Alto y Bajo Ampurdán”. La Federación, Barcelona, verano de 1872.

15 Memorias de un internacional es el subtítulo de El proletariado militante.

16 P. Gabriel coincide en que el proceso es más interno que imitativo (Cf.: « Sindicalismo y huelga. Sindicalismo revolucionario francés e italiano. Su introducción en España ». Ayer, n. 4, 1991, p, 34-41 y 44-45.

17 LORENZO, A., Op. cit., p. 286-303. 
de poner en dificultad, con algo de táctica, las reservas del capital, no respondía por consiguiente a una preocupación de orden sólo funcional -en el caso que lo " sindical » pueda limitarse a eso, para emplear una palabra que no usaba todavía el movimiento obrero en España ${ }^{18}$. Desempeñaba un papel sociopolítico en la perspectiva de rechazo de la participación política propia de la FRE, el cual, como se dijo, ya estaba presente, en parte, en textos del republicanismo federal y, también, en bastantes reacciones populares frente a las " autoridades -los « motines ", por ejemplo. La permanencia de la " organización », señal de su futuro y necesario crecimiento, fue, para la FRE, la vía para ampliar esa perspectiva propia. Ha llamado la atención la frecuencia del tema de la exaltación de la organización pero se ha interpretado sobre todo como indicio de radicalización venido con la identificación con la voluntad de revolución inmediata del bakuninismo, con sus evocaciones de una sociedad emancipada de todo tipo de " autoridad ", y no como forma de materializar en términos sociales más que ideológicos y políticos la perspectiva de ruptura de aquellos grupos obreros que se pueden calificar de « antitautoritarios » y que se sintieron concernidos por los temas generales del anarquismo. El presente trabajo quiere mostrar que la defensa prioritaria del instrumento organizativo lo fue de una identidad que se afirma en primer lugar como social y que genera una construcción ideológica duradera. Entrar en la llamada « política propia » ${ }^{19}$ suponía una constante preocupación por afirmar lo obrero construyéndole un espacio a la vez social y discursivo.

La necesidad, tantas veces repetida, de defender las organizaciones puede considerarse, en efecto, como la prolongación de aquella cultura política obrera que había empezado a elaborarse en los años 1860 y que cobró fuerza cuando el republicanismo no consiguió convencer de su compromiso con una sociedad libre y justa a unos colectivos obreros que dudaban de él y que pronto iban a tener a mano los esquemas bakuninistas, tanto más convincentes cuanto que parecían haber llevado a la constitución de un organismo nacional que se presentaba como exclusivamente obrero. Pero la inflexión, ya señalada, del proyecto bakuninista que los militantes libertarios más cercano a él no consiguieron imponer en su globalidad, suponía, según el discurso de la FRE, que todo había que tener lugar dentro del espacio obrero mientras que la lógica del primero lo llevaba a pensar también en el conjunto de la sociedad. El proceso de conversión de la defensa obrera en perspectiva política por la idealización que de ella se hace, tal vez pueda interesar una revista cuyo objeto son " os mundos do trabalho ». Confirmaría que éstos no fueron sólo un contexto en una fase en la que el tema de la ruptura política estaba en la orden del día. Al fin y al cabo, la transformación, aunque relativa en el caso español, de la situación de los asalariados y de su cultura del trabajo tiene consecuencias de orden político. Es tanto menos secundario que por toda la trayectoria del anarquismo español se siguió planteando la cuestión de las relaciones entre los componentes « sindicales » y los componentes « ideológicos». Dar cuenta del peso que llegaron a alcanzar las elaboraciones consideradas propias de los obreros puede sugerir preguntas para otros episodios de su historia.

Evocar la cultura política del anarquismo español supone por consiguiente tomar en cuenta una doble presencia, ideológica y de defensa obrera. No sólo porque a veces genera tensiones internas sino porque la inserción en la segunda es la que dibuja durante varias décadas no sólo modelos de acción sino un discurso

18 Tal vez porque, como veremos, la función no se distingue del proyecto político hasta que la prensa de información recorra al término usado en otras partes, en Francia en particular.

19 Cf. : La Emancipación del 10-VIII-1872. « Creemos que la Internacional tiene una política propia distinta de todas las de los partidos ». 
ideológico apoyado en las elaboraciones que acompañaron las prácticas obrera. Constituye una fuente imprescindible para entender la trayectoria de las iniciativas más visibles de lo que vino a ser la corriente libertaria en España. Su lógica configura las otras referencias y lo consigue en la medida en que las organizaciones obreras quieren ser el lugar exclusivo de acogida de la perspectiva de cambio de la sociedad. Para dar cuenta de su impacto parece lógico que en un primer momento se intente mostrar la continuidad en las actitudes y en los textos tanto del papel otorgado a la organización como del intento de imponer una forma de huelga - de hecho no se pueden separar. Proporciona muchos de los motivos que han podido contribuir, incluso cuando se debilitó el modelo, a que siguiera actuando entre los colectivos obreros una defensa prioritaria de la identidad social, fundamental en la cultura sociopolítica " antiautoritaria », la palabra más empleada, como se dijo, para significar una proximidad con los proyectos libertarios pero también con su inserción en términos propiamente obreros. Había identificación y diferencia al mismo tiempo ya que para unos y para otros las posibles confusiones no debían forzosamente ser aclaradas. El proceso de dicha idealización de la labor de organización puede tanto menos dejarse de lado cuanto que también está presente, al menos de forma indirecta, en los contenidos transmitidos por las formas menores, es decir no sindicales, de solidaridad, en particular el socorro mutuo. La presencia difusa de las huellas ideológicas de estas prácticas sociales confirmarían el sentido de la cultura política obrera a la que el presente estudio intenta hacer caso. Las reacciones internas y los discursos que suscitaron, tanto con los conflictos concretos como con las iniciativas de acción, han de examinarse, aunque de modo rápido, por un periodo más largo (1890-1902). Las divergencias suscitadas por la emergencia de « huelgas generales » a partir del cambio de siglo pueden ser consideradas, por ejemplo, como un indicio fuerte del impacto en la corriente libertaria, entendida en sentido amplio, de los modelos obreros que el estudio intenta analizar.

\section{Exaltación de la organización y resistencia centralizada}

La constitución de la FRE en el congreso fundador de Barcelona (18-26 de junio de 1870) confirmó con términos muy severos la importancia de la necesaria autonomía de la « clase trabajadora » con respecto al proyecto republicano y a las formaciones política que lo constituían. Desde unos meses existía una prensa propia que se presentaba como únicamente obrera y que precisamente dedicaba mucho espacio a justificar la forma de la organización que reuniría las asociaciones, al fin y al cabo de defensa " económica », que la formarían ${ }^{20}$. Correspondía a la nueva federación fortalecerla a través de los medios de defensa de los colectivos obreros, en particular los que le permitirían ganar huelgas. La organización se constituía, desde entonces como un fin en sí mismo - el objeto de la organización es la organización misma »-y en primer lugar porque era un espacio alternativo a la sociedad explotada por el capital ${ }^{21}$. La situación del asociado también afirmaba este objeto. Entraba menos en la FRE para participar en la consecución de un

20 La Solidaridad de Madrid sale el 15-I-1870. La Federación de Barcelona empieza el 1-VIII-1869 como « organo del Centro Federal de las Sociedades Obreras » para transformarse en órgano antiautoritario.

21 La Solidaridad, 17-IX-1870. 
objetivo que para " prácticar la solidaridad $»^{22}$. La cita es de principios de 1870. La " organización », es decir el proceso de asociación obrera, aparecía ya como un espacio con la vocación de totalidad del proyecto libertario, pero en una lógica predominantemente social.

El funcionamiento de una federación de secciones de defensa, de oficios en la gran mayoría de los casos, constituía por consiguiente una entrada en aquella sociedad nueva basada en la solidaridad, opuesta al egoismo de los capitalistas y de los burgueses. Funcionaría de manera « perfecta ${ }^{23}$ » ya que

[... ] una idea emitida por un individuo, en cualquier época o localidad, y que sea superior en verdad y justicia a lo que se practique, obtenga la sanción inmediata por parte de la sociedad [la organización] hasta que otra idea superior venga a reemplazarla, siguiendo los mismos trámites que la anterior ${ }^{24}$.

A la par que la organización se completaba entraba en una democracia aparentemente total, espacio verdaderamente alternativo al de la sociedad dominada y explotada por la burguesía: « La Internacional ofrece bien exactamente el tipo de la sociedad del porvenir y [...] sus diversas instituciones, mediante las modificaciones que convengan formarán el orden social futuro ${ }^{25}$. En otras palabras, todavía más precisas : "La sociedad futura no debe ser otra cosa que la universalización de la organización que la Internacional se haya dado. Así, pués, debemos tener cuidado de acercar todo lo posible esta organización a nuestro ideal $»^{26}$. Era la única vía para que no tardara en llegar aquella transformación radical de fuerte contenido moral : "Que en cada pueblo se establezca rápidamente una sección de la Internacional (sic) y la nueva sociedad aparecerá como por encanto para hacer desaparecer la vieja y sus vicios, o sean privilegios, un soplo ${ }^{27}$.

Son infinitas las variaciones sobre el tema de la organización que, abarcando ya parte del futuro al aislarse de aquella sociedad que se rechaza, lleva a una revolución social sin lagunas:

El proletariado moderno [...] ha escogido un terreno de acción propio, independiente de todos los partidos actuales y cerrado por su naturaleza a las invasiones de la clase enemiga. Así como en la Edad Media, el burgués se encerraba en la municipalidad y en el parlamento donde hallaba protección y garantías, el proletariado de estos tiempos se atrinchera en la Asociación obrera Internacional: organización de los trabajadores hoy, organización del trabajo mañana. ${ }^{28}$

Esta comparación la publica La Emancipación en mayo de 1872, es decir cuando el periódico está a punto de convertirse en el órgano del grupo marxista y de entrar en una polémica abierta con el antiautoritarismo. El grupo constituido alrededor de Lafargue justificaba su ofensiva porque había que combatir los intentos del bakuninismo de maniobrar a través de la sociedad secreta, " La Alianza ", que reunía a los militantes más directamente vinculados con la dirección de la corriente. En cambio, prácticamente no criticaba las posturas de defensa y

\footnotetext{
22 Idem, 5-III-1870

23 Idem, 12-III-1870.

24 Ibidem.

25 Idem., 5-III-1870

26 La Emancipación, 24-12-1871.

27 Ibidem.

28 La Emancipación, 16-V-1872
} 
de organización desarrolladas en los órganos de la FRE. El riesgo más subrayado era que la Alianza intentara alejar a la federación de sus principios fundadores o de sus reglamentos aprobados desde el Congreso de Barcelona. Al dejarse manipular por los partidarios de Bakunín los demás miembro exponían la federación al riesgo de su destrucción ${ }^{29}$. No fue solamente una postura táctica ya que el grupo de los futuros socialistas del partido obrero siguió identificándose con la exaltación de la organización. Incluso la UGT se construyó, en 1888, según el modelo de las cajas de resistencia de la FRE, prueba de que su modelo seguía teniendo un impacto en las modalidades de defensa -se ha subrayado a menudo que el fundador del PSOE y de su sindicato, Pablo Iglesias, exaltó sin descanso la necesidad de la organización. Es legítimo interpretarlo como una señal suplementaria de la presencia amplia de la efectividad de una cultura política, compartida más allá de la corriente libertaria y cuyos temas bien no se discutían o bien, en el caso de los bakuninistas, se comentaban con prudencia. Forma uno de los aspectos aparentemente paradójicos de la recepción del bakuninismo.

Justificar la separación de la política suponía que las modalidades de defensa sólo pudiesen ser interpretadas como totalmente obreras, pero para llegar a ello era preciso, al fin y al cabo, intentar transformar las huelgas reales. En primer lugar tenían que apartase de las intervenciones de orden político a las que a veces daban lugar los conflictos. Era inconcebible que los huelguistas siguieran usando alguna presión de ese orden ya que con ella políticos y notables penetraban en el enfrentamiento dando otra apariencia, engañosa, al conflicto, el cual sólo podía oponer a las dos clases que en realidad existían. El rasgo, al menos como tema, va a sobrevivir largo tiempo en los discursos anarquizantes. Para el periodo aquí tratado, conservaba su intensidad veinte años después de la fundación de la $\mathrm{FRE}^{30}$. Pero no siempre impedía que, incluso en las proximidades de la corriente libertaria apareciesen tentaciones para aprovecharse de alguna disponibilidad de las instancias locales o provinciales para obtener concesiones patronales. En las conductas posteriores de los componentes sindicales de la corriente libertaria pudo haber distancia con respecto al modelo y alguna vez alguna moderación discursiva. En cambio, en la vida pública de la FRE, la exigencia se expresó de modo drástico. Se trataba de dejar claro que las instituciones y las instancias políticas no tenían otra razón de ser que la de defender los intereses burgueses, lo cual sólo podía alcanzarse situándose en un campo exclusivamente social en el que se enfrentarían sólo obreros y patronos. El modelo de huelga quería demostrar precisamente que sólo existían dos espacios, el de los explotadores y el de los explotados, el del trabajo frente al del capital.

Identificar la defensa económica y social concreta con la perspectiva de una acción emancipadora, suponía una necesidad de resultados para la primera. Resultó imposible, sin embargo, que, a no ser en unas ocasiones excepcionales, la federación consiguiese ayudara los huelguistas que lo necesitasen. Para constatarlo no fue necesario esperar el crecimiento de la conflictividad en los años 1872-1873. La vía elegida sólo podía funcionar modificando casi totalmente las prácticas. Antes de que la federación hubiese acumulado unas reservas importantes no podía intervenir prácticamente en ningún conflicto -algo bastante lejos, por consiguiente, de un objetivo visible. Durante un breve espacio de tiempo (1870-1871) la imposibilidad de ayudar a los huelguistas pudo ser atenuada por el gran cambio que anunciaba la existencia de la federación pero no cuando las

29 Es el tema de la polémica con La Federación en el verano 1872.

30 Se desarrolla en el apartado "El antiestatismo como sustituto del enfrentamiento decisivo. Mantener la ruptura". 
secciones se encontraron frente a la obligación de tener una caja de resistencia y de pedir cuotas para entregar una parte de ellas a la central de la federación. Ya que la gestión de la defensa social concernía al corazón mismo de la identidad obrera, la huelga, el poder de convicción de la FRE dependía en gran parte de la posibilidad de ayudar a enfrentar los conflictos de trabajo que surgiesen para que, por una parte, mostrasen una defensa sin concesiones de su dignidad y, por otra parte, venciesen. De hecho, lo que el análisis ha solido considerar desde fuera como de orden sindical, entendido como el espacio de cierto pragmatismo, dió lugar a unas reglas invariables y abstractas. La necesidad de consolidar las cajas de resistencia propias y obligatorias de las secciones de base o de las uniones, el nivel intermedio, impedía que una sección entrara en una huelga sin tener medios numerarios suficientes para sostenerla y ello no existía. El éxito de una iniciativa particular sólo podía alcanzarse si las entidades patronales tenían una necesidad absoluto que el trabajo continuara en sus establecimientos o si se encontraban en la imposibilidad de conseguir sustitutos a los huelguisas, casos muy poco frecuentes. La decisión de una organización local estaba, por consiguiente, subordinada a la de la instancia superior. Una de las justificaciones de los derechos de la federación de aprobar o no las huelgas era que ella iría adquiriendo el conocimiento, que las secciones no estaban en condiciones de alcanzar, del estado preciso de las variables que podían llevar a los patronos a ceder, como la demanda de trabajo en un oficio o en un ramo, la dimensión de las ganancias patronales en un momento dado, las posibilidades de contratar en otros lugares mano de obra especializada, etc.. Formaba parte de una llamada " preparación científica de las huelgas "31. La idealización del arma obrera por excelencia, la que permite precisamente hacer visible la barrera que separa de modo drástico la " clase trabajadora » de las demás, desembocaba por consiguiente en una desconfianza con respecto a las convicciónes que podían formarse en un momento dado los colectivos obreros. Venía a ser algo contradictorio con la atención que les otorgaba la prensa obrera y también con la idea de la capacidad de la clase para rechazar su integración. Puesto que los éxitos de las huelgas eran necesarios para savalguardar la existencia de la federación obrera pero que, por otra parte, la capacidad de conseguir algunos dependía de una potente organización, el camino no tenía muchas salidas.

Es de notar que las modalidades de la organización y de la caja central de resistencia se fueron haciendo más precisas a medida que tuvieron lugar los congresos o conferencias que siguieron al inaugural de Barcelona. Durante cierto tiempo creció la convicción a su respecto. Era probablemente grande la de Anselmo Lorenzo cuando, elegido representante de la FRE para la conferencia de Londres de la AIT, en el verano de 1871, presentó a los demás delegados la propuesta de una caja de resistencia universal, la cual correspondía a la última versión de los estatutos de la FRE ${ }^{32}$. No correspondía por supuesto a la orientación de los partidarios de Marx ni a la de otros militantes obreros. Tampoco parece haber despertado interés entre aquellos que apoyaban el rechazo bakuninista de la participación política sustituyéndola por la capacidad de rebeldía de los oprimidos ${ }^{33}$. La preocupación

31 La Emancipación, 11-V-1872 « [... ] se conseguirá preparar las huelgas científicamente y preparar su triunfo antes de llevarlas a cabo, haciendo de este modo morder el polvo a la burguesía capitalista ». Es corriente la convicción que la estadística puede ser un arma decisiva (Cf.: MYSERWICZ, L. « Karl Marx, la Première Internationale et la statistique, ». Le Mouvement Social. n 69, octobre décembre déc. 1969, p.51-84).

32 Era la aprobada en la Conferencia de Valencia de 1871. Editada bajo el título Organización social de las secciones obreras de la FRE, Valencia, 1871.

33 La única contestación bastante larga fue la de un delegado inglés en la conferencia, Motterhead. Además de subrayar que en una caja de resistencia universal las decisiones escaparían a los afiliados añadió : « [...] tienen los obreros un derecho no enajenable, el de rebelarse y perciben y juzgan mejor que el Consejo 
de la conferencia era muy distinta : se había convocado porque en la cuestión de la participación en la política se enfrentaban marxistas y bakuninistas. No es imposible que A. Lorenzo percibiera la propuesta de una federación de resistencia universal como una manera de dar una salida a la oposición entre " políticos » y « antipolíticos » poniendo a todos los sectores obreros dentro de un espacio propio y socialmente homógeneo. Al menos con un carácter exclusivamente obrero y un número razonable de asociados una organización aparentemente compartida por las dos orientaciones podría borrar bastantes desacuerdos. Correspondía al proyecto sobre el que se había construido la FRE.

La federación española no se planteó por consiguiente la pregunta de su distancia con la temática ideológica bakuninista. La mayoría de los militantes no lo consideraron contradictorio con lo que creían saber de las perspectivas propiamente libertarias tales como las reconocían implícitamente. Las críticas, veladas o abiertas, que se hicieron a veces al modelo de huelga de la federación se dirigieron contra su demasiada rigidez sin traducirse en alguna inflexión a pesar de que las dificultades acarreadas por la intensificación del movimiento de huelgas en 1872-1873 suscitaron más comentarios al respecto. Algunas de las personalidades de convicciones bakuninistas empezaron entonces a criticar de manera directa las modalidades de solidaridad. Fue el caso del autor de una serie publicada en el periódico antiautoritario de Barcelona, el mas leido de la fase de la FRE, La Federación :

Siendo lo esencial [...] la organización, la quieren tan perfecta hasta en sus detalles, que más bien responden a las necesidades del porvenir que a las del presente; más bien una organización positiva que negativa; una compañía que recauda y distribuye, que da cuentas y pasa balances, que suprime o añade artículos del reglamento; que un grupo revolucionario que se agita en virtud de un nuevo principio ${ }^{34}$.

Pero durante sus dos últimos años, las direcciones de la federación, a pesar de tener que confesar cada vez más su impotencia frente a las peticiones de ayuda de muchos colectivos que habían entrado en conflictos, siguieron insistiendo en la necesidad de dar prioridad a la defensa de la federación contra lo que interpretaban como una ligereza de los colectivos que decidían ponerse en huelga35. La culpa no se echaba al sistema de ayudas condicionales sino a la incomprensión de unos obreros que sólo esperaban que la federación cumpliera con la solidaridad anunciada. No estaban a la altura del gran compromiso de la FRE :

Es muy sensible que sólo con el aliciente de la huelga entren los obreros a formar parte de Nuestra Asociación (sic) eminentemente revolucionaria, cuyo fin es mucho más grande y no adopta ésta sino como remedio para mejorar por lo pronto la miserable situación de sus afiliados. La práctica nos ha mostrado que todos aquellos que son internacionales por la huelga y que no ven otra cosa, dejan de serlo cuando pierden una ${ }^{36}$.

Estas líneas son características de las contestaciones de la Comisión federal de la FRE a las secciones que pedían ayuda insistiendo en la urgencia de recibir algo. Las escribe en una carta a la « Unión de noografos » (papeleros) Severino Albarracín,

Federal la necesidad de hacer una huelga ; el consejo sería impotente para impedírselo además de no estar dispuesto a entrar en una lucha con los patronos para conservar su haber » (FREYMOND, J. (dir.). La Première Internationale. Recueil de documents. Genève: Librairie Droz, 1962, tomo 2, pp. 178-179).

34 "Cartas a los trabajadores del Alto y Bajo Ampurdán". La Federación. Carta IV (Barcelona, 14/09/1872).

35 SERRANO; SAS. Op. cit., v. V a VII.

36 Contestación del 26-V-1873. En: SERRANO; SAS. Op. cit, tomo IV, p. 287. 
uno de los responsables más habituales de la " comisión federal » cuando ésta reside en la región de Valencia. Según $M$. Nettlau, el historiador anarquista que desde más cerca miró, en los años 1920-1930, la vida de la corriente, S. Albarracín compartía la " inclinación organizadora catalana » lo que lo distinguía en cierta medida de los militantes más explícitamente bakuninistas ${ }^{37}$. Aunque no formó parte de los primeros miembros españoles de la «Alianza » sus palabras oponen sin embargo convicción revolucionaria y acción obrera. Lo más significativo no es que existiera una divergencia sino que los dirigentes de la FRE continuaran asumiendo el modelo de organización cuya importancia quiere subrayar el presente artículo, al mismo tiempo que sus dirigentes siguieran admitiendo, al menos formalmente, los grandes rasgos del bakuninismo. Se trataba de asumir la lógica de separación, de naturaleza social, sobre la que, empezando por una organización, se quería construir el espacio obrero emancipado y emancipador.

\section{Aplazamiento del conflicto decisivo}

No sorprende que con tal visión de la acción desapareciera de los objetivos el conflicto decisivo, aquel que los esquemas bakuninistas imaginaban repentino y con capacidad para conseguir el cambio de la sociedad. De hecho, los antiautoritarios, pero también parte de los que se sentían más ideológicamente anarquistas, estaban dejando de lado, y para bastante tiempo, un tema tan central y emblemático de la ruptura social como la huelga general, ya esbozada en los debates de la Primera Internacional fuera de España ${ }^{38}$. Había llegado de manera algo velada a España un poco antes de que el Congreso de Barcelona discutiera de los medios de acción. El siguiente extracto de una de las intervenciones de Anselmo Lorenzo en dicha reunión muestra que, a no ser el sintagma todavía poco sistematizado, estaba la modalidad :

[...] nosotros, trabajadores, por medio de una resistencia universalmente organizada, destruiremos por completo los inmensos medios de los que disponen nuestros enemigos, obligándoles a abandonar sus injustificables privilegios, por que ellos son impotentes para resolver nada ante una abstención general de los trabajadores ${ }^{39}$.

Es significativo que la huelga que se evoca aquí, y a pesar de sus consecuencias globales, oponga sólo a los dos únicos interlocutores fundamentales según la visión ya señalada del conflicto decisivo. Lo es también que suponga la construcción de una organización considerable. Sólo alguna vez se la relaciona más directamente con la «Revolución Social »:

La huelga general es indudablemente el acto más grave, más importante y más trascendental que la clase obrera viene a realizar en el transcurso de la humanidad; es el objeto de nuestros trabajos, de nuestros desvelos ; es el término de la odiosa explotación que por espacio de tantos y tantos siglos, viene pesando sobre la que se considera la última capa social ; es el fin de la miseria y la ignorancia ; es el juicio inexorable que el obrero de la presente sociedad; es el despertar de la humanidad a la aureola de la nueva vida, un nuevo orden de cosas; es transportarse

37 NETTLAU, M. La Première Internationale en Espagne (1868-1888). Colocar o restante da referrência, p. 124.

38 Por otra parte, la cuestión de la huelga universal entra en los debates de la Primera Internacional en el congreso de Ginebra (septiembre de 1866) (Cf.: FREYMOND, J. Op. cit., tomo 1, p. 44).

39 ABERLOA, V.M. (ed.). I Congreso obrero español. Madrid: ZYX, 1972, p. 179. 
desde el mundo de la mentira, la explotación y el crimen al mundo de la verdad, de la justicia y de la fraternidad humana ; es, en fin, le Revolución Social $»^{40}$.

Se publica este texto cuando está cerca de acabarse la vida publica de la FRE y con pocas perspectivas frente a la inflexión autoritaria de la República, la cual anuncia su fin. A partir de entonces la huelga general casi no se va a mencionar como tal durante casi veinte años. Serán necesarios casi diez más para que sea asumida concretamente, y con las palabras habituales, como modalidad de acción mientras existía, al menos a nivel de discurso, en otros espacios nacionales. Un estímulo venido de fuera del antiautoritarismo la hizo aparecer de nuevo. Fue la « fiesta del trabajo ", primera gran iniciativa de la nueva Internacional (la "Segunda ») en su congreso fundador de París en 1889. La modalidad propuesta era la manifestación de masas que las organizaciones obreras habían de llevar cada primer día de mayo. Con ella se ejercerían fuertes presiones a nivel social y político para conseguir medidas legales de protección social y, sobre todo, una disminución de la jornada de trabajo con las " ocho horas ». Para la sensibilidad anarquista era necesario mostrar su diferencia tanto a nivel de la perspectiva de la acción -para la nueva Internacional el estado era un interlocutor que debía tomar medidas legislativas- como de su forma -los socialistas proponían un movimiento más visible por su intensidad que por su duración, excluyendo las situaciones de todo o nada en las que la corriente libertaria veía la posibilidad de entrar en el enfrentamiento definitivo.

Si sólo entonces se llegó a incluirla en las perspectivas fue porque las reglas de la FRE en materia de organización y de acción habían significado bastante más que una función práctica sin muchas consecuencias ideológicas. El que la línea inicial haya tenido grandes dificultades, manifiestas en la impotencia para dar credibilidad al espacio obrero que habían de constituir las organizaciones no puede hacer olvidar que el intento existió y duró más allá de la vida pública de la FRE. Es decisivo al repecto el testimonio de la correspondencia dirigida a las secciones ya que las contestaciones subrayan la necesidad de proteger antes que nada la organización, espacio obrero separado que constituye un objetivo en sí mismo. A pesar de la falta de éxitos concretos se consolidaron unos esquemas que fueron constituyendo una cultura política obrera algo distinta, como ya se dijo, de la propiamente bakuninista. Dejarla de lado significaría seguir prescindiendo tanto de las relaciones entre proyectos de cambio social y modalidades de acción de los diversos sectores obreros como de las preocupaciones por estructurar un espacio obrero en el que los colectivos de la clase consiguieran situarse en un marco político en el que los componentes populares querían entrar de forma autónoma -era un objetivo bastante compartido desde que la corriente libertaria había asomado. Intentar conseguirlo hacía emerger unas situaciones contradictorios a las que se contestaba con los modelos y los discursos que acabamos de evocar.

Se consideraba como absolutamente prioritaria a la organización porque se la veía como un espacio ideal y unívoco fuera de los espacios concretos de la vida política. Convertirlo en el de los obreros suponía que el intento de controlar las huelgas no fuera sólo verbal -ya se han dado ejemplos de que no lo fue. Si una elaboración tan ambiciosa tuvo lugar fue porque la defensa de un espacio estrictamente obrero, con toda la alternativa que representaba frente a las perspectivas republicanas, llegó a ser una construcción ideológica articulada y

40 La Federación, 27-IX-1873. 
no sólo una recuperación de prácticas de defensa con su carga táctica, capaz de apartarse de los choques sin preparación del bakuninismo, los cuales también respondían a un estado de espíritu bastante corriente en los sectores populares españoles. Son ocurrencias de aquella cultura obrera que el presente artículo intenta describir.

Conseguir la inserción social del proyecto anarquista se había convertido en una necesidad cuando unos militantes obreros lo prolongaron hacia colectivos de trabajadores por medio de unos primeros periódicos y de una federación nacional de sociedades de resistencia. Hasta entonces no había conseguido, sino de modo marginal, ser un movimiento de ideas con eco en otros ámbitos sociales. Ello tardaría algunas décadas y se revelaría difícil precisamente porque la perspectiva, aparentemente libertaria, tomó una fuerte tonalidad obrerista desde el principio. Pero por ser reflejo de la cultura sociopolítica obrera más que de una temática ideológica los modelos de organización y de acción definidos por el primer congreso introdujeron un desfase con la perspectiva de emancipación dibujada por el bakuninismo. Cuando A. Lorenzo lleva el proyecto de « organización social » a la conferencia de Londres de 1871, está probablemente convencido de que los artículos que lo componen resuelven las tensiones que percibía, igual que algunos grupos de internacionalistas, entre la referencia global y las propuestas elaboradas por la federación. Para ambos aumentaron en los años 1880 cuando tuvo lugar, con la FTRE, el intento de reproducir la FRE y aún con mayores dificultades para conseguir que las secciones más combativas llevaran a la mayoría de ellas a que adoptaran su tipo de presencia social ${ }^{41}$. Es muy significativo que a A. Lorenzo, a pesar de su sinceridad, le costó dar cuenta de cómo la FRE había adoptado su modelo inicial de huelgas. Cuando, en 1901, insiste en que fue una vía equivocada echa la responsabilidad a unos jóvenes intelectuales

[... ] relacionados con los trabajadores asociados de Barcelona, y miembros activos de la Alianza de la Democracia Socialista [quienes con ocasión del primer congreso] forjaron una organización que era un mecanismo perfecto al que no llegaba la mentalidad ni las costumbres de los trabajadores españoles en general ${ }^{42}$.

Por cierto, hubo en los primeros pasos de la FRE un grupo de estudiantes y algunas personalidades no obreras que contribuyeron a darle una visibilidad política ${ }^{43}$-en Barcelona, más que en otras ciudades, las relaciones seguirían existiendo. Pero sólo sería convincente la interpretación de Lorenzo si el funcionamiento del Comité federal y de la Comisión federal durante los años 1872 y 1873 , no hubiese estado bajo la responsabilidad de cuadros obreros. Ellos fueron los que recordaron con una gran constancia los requisitos a observar en caso de intención de declararse en huelga ${ }^{44}$. No es muy nítida, además, la interpretación de Lorenzo en lo que se refiere a la aportación obrera a la FRE. Al evocar, el primer congreso, distingue varias corrientes entre los delegados, subrayando las calidades de la "idealista revolucionario ", la cual " iba directamente a la renovación de la sociedad ", y distanciándose de la " societaria, que entusiasta y apasionada por las sociedades (« asociaciones » M. R.) constituidas, mirando con

41 La insistencia en la proximidad de la FTRE con respecto a la FRE en los artículos del militante antiautoritario Francesc Tomàs i Oliver (1850-1903) en su serie "Apuntes históricos. Del nacimiento de las ideas anarcocolectivistas en España”, publicada en La Revista Social entre el 27 de diciembre de 1883 y el 15 de enero de 1885.

42 LORENZO, A. Op. cit., p. 287

43 NETTLAU. Op. cit., p. 52-91.

44 Cf.: SERRANO; SAS. Op. cit., v. IV a VII. 
desconfianza las novedades de la organización obrera, tenía escaso entusiasmo por los grandes ideales ${ }^{45}$. Como ya se dijo, cuando Lorenzo publica la primera parte de sus memorias se han agudizado las tensiones entre un concepto de huelga general definida como primer paso hacia el conflicto decisivo -lo difunden los periódicos libertarios La Huelga General y El Productor (segunda época de este título) - y una visión sindical de ésta que la ve como una forma de acción más ancha, menos temerosa de pasar de los límites que separan unos oficios de otros, pero no como un primer paso hacia un conflicto que podría convertirse en global. No es necesario decir que, para el libertario A. Lorenzo, la capacidad emancipadora la tiene la primera -por ello sus memorias tal vez olvidaran su apego anterior al papel de aquella organización considerada como " completa » por la prensa internacionalista. Era la que, él mismo, había llevado a Londres. Aquellas palabras de El proletariado militante contribuyeron probablemente a que quedara borrada para bastante tiempo la lógica inicial de la construcción organizativa de la FRE.

En los intentos de dar cuenta de ella es notable que pocas interpretaciones establecen una relación entre el modelo y los estatutos sociales que componían el mundo obrero español. Tal vez porque es difícil sacar una percepción unívoca de las elaboraciones de la FRE y, después de ella, de los componentes radicales del movimiento obrero. Pero ya a primera vista, el modelo de organización tan subrayado en el presente artículo parece bastante más cerca de los obreros de los oficios que de las otras categorías. Podían abonar una cantidad mensual porque sus ocupaciones eran más estables y mejor pagadas -era mucho más difícil para los asalariados más informales o precarios. Más que otros podían creer en las virtudes de la organización puesto que la gran mayoría de las iniciativas de defensa tenían lugar alrededor de un oficio. Incluso cuando tardaban en formalizarse a través de una « sociedad » de defensa, los trabajadores de una especialidad solían tener una vida de comunidad de la que se pueden citar muchos ejemplos ${ }^{46}$-además en los conflictos los obreros de un oficio pocas veces salían de los límites del suyo ${ }^{47}$. Asoma, a veces, en los discursos la intención de atraer primero a los más educados, a los que ocupan empleos que suponen un largo aprendizaje -su duración era el argumento de los obreros de oficios para defender su nivel de sueldo. Es muy significativo también que ello no impide que se considere como única la clase obrera y que se evoque su versión española como si fuera prácticamente la misma que las de los paises más avanzados. Lo necesitaba la función que cumplía el mundo de los asalariados manuales en el proyecto radical de separación con " la política burguesa », el cual implicaba que lo obrero constituyese un actor exclusivo y sin matices. Las experiencias obreras seguían recordadas, sin embargo, a nivel implícito ya que el argumento decisivo de la separación se apoyaba en la experiencia cuotidiana de lo obrero -esto es de las formas, y del discurso, que tomaba su defensa social.

Ese apego ambiguo a la unidad parece dar cuenta, al menos en parte, de la relación de la sensibilidad anarquista, con la renovación de sus referencias

45 LORENZO. Op. cit., p. 107. Las otras dos corrientes son «la positiva », se refiere a las organizaciones pragmáticas del textil catalán que practican la negociación, y la política, la cual deseaba un acercamiento con el partido republicano federal. En la introducción de su Antología documental del anarquismo español, F. Madrid y A. Venza (Fundación Anselmo Lorenzo, Madrid, 2001, v. 1, pp. 26-28) también consideran que si consiguió constituirse el « entramado organizativo » de la FRE fue porque hubo dentro de ella un acuerdo global a su respecto.

46 En F. Largo Caballero (Correspondencia secreta, Madrid, Nos, 1961) muchos ejemplos acerca de los « estuquistas » de Madrid.

47 Cf.: RALLE, M., «Las huelgas antes y después del Primero de mayo ». Estudios de Historia Social, n. 54-55, 1991, p. 32-34. 
ideológicas en los años 1880. Las historias políticas del anarquismo español señalan que entonces no sólo se interesó por las nuevas propuestas transmitidas por los escritos de Malatesta, Kropotkine, Grave, etc. sino que sus publicaciones tendieron a identificarse al anárquico-comunismo, y en particular al segundo de los tres, alejándose del " colectivismo » con el que se definía a Bakunin, o al menos matizándolo ${ }^{48}$. No es secundario que los anarquistas españoles imaginaran la sociedad futura no como la que permitiría que cada productor recuperase el " producto íntegro » del trabajo, según un esquema proudhoniano admitido por Bakunín, sino que intentasen encontrar los medios para que, además de los obreros que producían ganancias, la sociedad entera recibiese sus efectos ${ }^{49}$. Se enriqueció el discurso libertario y ello contribuyó a que el movimiento estuviese un poco más presente a nivel intelectual -lo demuestran los dos "Certámenes socialistas ", el primero en 1885 y el segundo en $1889^{50}$. El que se intentara corrresponder a las definiciones que estaba usando el movimiento libertario a nivel internacional proporcionaba un estatuto intelectual frente a la emergencia, tardía, en España de una vertiente marxista que había demostrado, en otros paises, su capacidad tanto para articular su presencia política e intelectual como para disputar el espacio público con propuestas políticas y prácticas sociales. En España, sin embargo, los nuevos postulados asomaban en un periodo en el que ni las tensiones políticas ni los débiles movimientos sociales proporcionaban muchos ejemplos para renovar los comentarios sobre la sociedad. La política estaba controlada por el sistema instalado por el nuevo régimen. Los intentos republicanos sólo se limitaron en los años 1880 a unos esbozos de pronunciamentos de simpatías republicanas como el del «brigadier » Villacampa en 1886, carente de movilización popular y rapidamente abortado. Ese relativo vacío puede explicar que muchos de los militantes libertarios más activos, más bien que intentar dar más consistencia a su identificación con las nuevas definiciones que habían emergido en el movimiento, insistieron en su pertenencia global a una « anarquía sin adjetivos », una fórmula a menudo repetida ${ }^{51}$. La actitud es lógica sobre todo si la relacionamos con aquella preocupación del conjunto auntiautoritario por afirmar en primer lugar la pertenencia a lo obrero, lo cual suponía que se subrayara la necesidad de un espacio político y discursivo que lo fuese exclusivamente. Al fin y al cabo era también una manera de atenuar la preocupación por los debates de orden ideológico y por mantener una definición de orden social de lo obrero.

\section{Algunas premisas de la idealización de la asociación.}

Ya fue señalado que el proceso de idealización de la asociación también tuvo un pasado en los imaginarios políticos y encontró algún que otro ejemplo en prácticas sociales diversas. A partir de los años 1860 los círculos obreros y las

48 Una síntesis de las divergencias ideológicas en JUNCO, Op. cit., p. 353-368.

49 Escribe La Justicia humana de Barcelona en su número de1 18-IV-1886 : « [... ] ni el temperamento y las condiciones físicas pueden ser nunca el resultado de un esfuerzo individual y que el privilegio de utilizar sus aptitudes más o menos activas en beneficio propio es sustraerse a satisfacer a la sociedad los beneficios que de ella misma recibiera ». Citado en JUNCO. Op. cit., p. 362.

50 Primer Certamen Socialista, Barcelona, Imprenta de Pedro Ortega, 1885, LXII-576p. y Segundo Certamen Socialista celebrado en Barcelona el dia 10 de noviembre de 1889, Barcelona, Establecimiento Tipográfico "La Academia», 1890, 440 p (Cf un análisis en MORALES, Manuel. «La subcultura anarquista en España: el primer certamen socialista (1885): en Mélanges de la Casa deVelázquez. tomo 27-3, 1991. p. $47-60$ y « El segundo certamen socialista, 1889: notas para un centenario ». En: Mélanges de la Casa deVelázquez. tomo 25, 1989. p. 381-395.

51 JUNCO, J. A. Op. cit., p. 365, señala que se encuentra en el « Segundo certamen », celebrado en 1889. 
" sociedades de defensa » habían ido adquiriendo unos esquemas y un vocabulario tanto por sus contactos con algunas propuestas políticas como por las formas obreras de solidaridad que les podían servir de modelos. Su impacto lo hizo mayor el antipolitismo popular, en sentido amplio. Las imágenes más visibles de relaciones libres e iguales y la idealización de la asociación las había proporcionado en parte el discurso federalista mientras el socorro mútuo contribuyó a la idealización de la segunda.

a) La contribución del republicanismo federal.

En la década de 1860 la corriente difundía unas propuestas de construcción de una sociedad ideal a partir de la autonomía de las comunidades de base -en este caso las locales, algo idealizadas. Constituye una prueba de la relativa presencia de un visión antipolítica en los espacios sociales populares. Ya se dijo a propósito de la difusión del bakuninismo y de las relaciones de personalidades de la FRE con algunos de sus representantes, en particular la « Fédération jurassienne » de Suiza, que la elaboración ideológica y las formas de acción no fueron el resultado de una simple transferencia del bakuninismo. No fueron muchos, además, los textos de Bakunin publicados en los periódicos habituales de la FRE -los folletos sólo se traducen, algunos, en los años $1880^{52}$. Distanciarse del republicanismo federal no significaba que los modelos de relaciones sociales por los que éste se había pronunciado cayeran en desuso al ser abandonados los objetivos políticos del federalimo. Incluso algunas veces los antiautoritarios, se presentaron, en particular al principio, como los más capaces de realizar su espíritu porque su condición social les daba la capacidad de establecer unas relaciones justas en su espacio organizativo.

En 1868, los temas del republicanismo federal ya tenían una trayectoria consistente. Los habían difundido personalidades como F. Garrido y F. Pí y Margall. Intentaban responder a las interrogaciones que sobre lo político alimentaba un estado débil y autoritario a la vez, el cual se preocupaba más por controlar, con dureza, la sociedad que por construir una adhesión social a una forma política. Ello reforzó las actitudes de rechazo popular a los instrumentos que se consideraban propios del estado. El régimen que sustituyó a la República, una monarquía semiautoritaria y semi-parlamentaria, acentuó, él también, los motivos de desconfianza hacia un estado que los había suscitado a pesar de su inflexión liberal despues de 1833. Las fuerzas políticas de intención democratizadora también se encontraban afectadas por parecer cómplices del edificio institucional. La relación privilegiada que los federales querían mantener con el conjunto de las variantes republicanas hacía difícil que su construcción política consiguiera conservar todo su impacto entre los componentes obreros que ya miraban más hacia la separación ${ }^{53}$. Sin embargo, el que la perspectiva de los federales de construir un poder político desde la base puede haber contribuido a que se impusiera como forma de relaciones en muchos colectivos obreros. Proponer que el cambio político se articulase a partir de las unidades de base consideradas como una alternativa global al sistema político era un tema muy frecuente desde casi veinte años : F. Garrido ya había publicado en 1855 un folleto en este sentido, La república democrática, federal, universal, tantas veces reeditado que hay como una continuidad de su lectura54. Variante del federalismo proudhoniano actua en sentido antipolítico a pesar de la intención de su autor. También lo hicieron aquellas obras de Proudhon traducidas por el catalán

\footnotetext{
Cf.: Lista de publicaciones en JUNCO, Op. cit., p. 635-636.

53 ARRANZ, L; ELORZA, A. «El Boletín de las clases trabajadores... », p. 371-381.

54 1. ${ }^{\mathrm{a}}$ ed. en $1855,2 .^{\mathrm{a}}$ en $1856,7^{\mathrm{a}}$ en $1868,16^{\mathrm{a}}$ en 1873.
} 
F. Pi y Margall, la personalidad más conocida del federalismo. Con la construcción de un espacio independiente de las formas habituales de poder y también, en cierta medida, de un sistema representativo con un sufragio más formal que efectivo, el federalismo contribuyó a que parte de las opiniones populares aceptasen las posturas radicales de la separación a través de una federación de asociaciones autónomas. Con la confluencia del bakuninismo y de una federación de defensa de la clase la lógica de la pertenencia social, estableciendo un espacio que permanecería propio, apartó la sensibilidad obrera, seducida en un primer momento..

Si ya no parecía convincente la forma de reunir las distintas instancias desde la base hasta la cúpula de la nación, e incluso más allá, proporcionaba sin embargo un modelo para una construcción que buscaba un funcionamiento ideal. El de una nueva república en la que que todos, además de acceder a las libertades individuales y políticas, podían convivir con una igualdad implícita, seguía siendo un tema central en el federalismo. Sugería que era posible acceder por la vía de la asociación a una sociedad futura. Lo decía un periódico federal en estos términos :

[...] lo más esencial e íntimo que hay en nuestro tiempo : la asociación, la santa asociación ; esa unión fraternal, esa comunión libre de los hombres, amparados por todos los pueblos civilizados, consagrada en las leyes, mirada por los pensadores como el cimiento de una nueva vida pacífica, fraternal, feliz, sin guerras y sin los horrores que ennegrecen los siglos que dejamos atrás, durante los cuales ha dominado como dueña absoluta la Iglesia católica. / Esas sociedades de mutualidad de socorro, amparo, de confraternidad, son el santuario de la civilización, y hay que respetarlas más que a los santos que se adoran en los altares. Aquí hay ídolos, materia, formas, ya vanas ya impotentes. Allí hay esencia, hay alma, hay espíritu55.

Estas frases constituyen une prueba de la preocupación republicana federal por los sectores populares con una atención particular a los obreros. Muestran que desde tiempo la sensibilidad antiautoritaria había podido encontrar motivos para otorgar a la asociación la virtud de combinar la ayuda concreta que necesitan quienes cobran un salario y los rituales de sociabilidad de los círculos republicanos ${ }^{56}$. Correspondía a lo que se estuvo implantando progresivamente a pesar de las críticas, en un primer momento, del obrerismo, es decir las sociedades de socorro. Su impacto relativo participó del proceso de idealización de la asociación. Su existencia y su trayectoria no son nada secundarias en la elaboración de la cultura política obrera que va cuajando en los años de la FRE.

b) Las iniciativas de solidaridad. La capacidad infinita de la asociación

La historiografía tardó bastante en prestar atención a las iniciativas obreras que se pueden calificar de modestas ${ }^{57}$. La cooperación se estudió un poco más : parecía anunciar las ulteriores propuestas de separación de la clase al mismo tiempo que constituía una vía de acceso a los espacios obreros para unas opciones políticas, bien el reformismo social o bien el catolicismo social -aunque menos el segundo- que la siguieron defendiendo como respuesta a la cuestión social. La educación y las actividades de orden cultural, desde la alfabetización hasta la práctica del teatro o de la poesía en los círculos obreros, interesaron por sus

55 Las Dominicales del Libre Pensamiento, 20-IX-1890.

56 Entre ellos el banquete llamado de « promiscuación ». Para la sociabilidad republicana una evocación de su lógica en DUARTE I MONTESERRAT, A.. Possibilistes i Federals. Política i cultura republicanes a Reus (18741899), Reus, 1992, p. 145-157.

57 El primer coloquio sobre el socorro mútuo en España tuvo lugar en 1992. Las actas en S. Castillo. Solidaridad desde abajo. Madrid: UGT-Centro de Estudios Históricos, 1994. 
intentos, trabajosos, de constituir una cultura obrera que se distinguiera de la dominante. Al socorro mutuo, durante tiempo, sólo se le reconoció una función transitoria que la emergencia de la organización obrera radical habría convertido en obsoleta. Los militantes más conocidos, al recordar a veces las primeras formas de su experiencia obrera, reproducían la misma jerarquización : el mérito del socorro mutuo había sido de hacer más llano el camino hacia el ingreso en la organización de clase cuando ésta apenas existía ${ }^{58}$. Las críticas intermitentes de la prensa obrera radical contra el carácter ilusorio de las asociaciones de socorro mútuo -a veces llamadas por sus nombres tradicionales de " montepíos » e, incluso, de « hermandades »- parecían justificar la indiferencia de la investigación a su respecto. Subrayaban que su funcionamiento era burocrático y que podían llevar a los obreros hacia soluciones parciales que se revelarían falsas o permitirían manipulaciones patronales.

El silencio ha durado mucho. No parece justificado si se tiene en cuenta que paralelamente al aumento de las actividades de organización social y de la militancia política obrera también el número de las sociedades de socorro creció, y de manera notable, además, entre los años finales del siglo XIX y los iniciales del $X^{59}$. El éxito se puede atribuir en parte, y no carecería de sentido, a la ausencia del estado español en la protección social. Al contrario de lo que pasa en la Francia del Segundo imperio (1851-1870) donde el estado no deja que el movimiento de socorro se desarrolle lejos de su control no hay en España voluntad institucional ni de desviar las iniciativas hacia horizontes conocidos -se confía en la Iglesia para que desempeñe este tipo de papel ${ }^{60}$ - ni de preocuparse por ejercer un control, a no ser el de orden público que obligaba a las asociaciones a que pusieran sus libros de actas a disposición de los gobiernos civiles. Se dan casos de rechazo de eventuales cajas patronales de enfermedad que combinaban intentos de integración en el lugar de trabajo y modalidades de exclusión de los obreros considerados como rebeldes -en los años 1880 parecen estar en declive ${ }^{61}$. De hecho el socorro mutuo había llegado a ocupar cierto espacio que los socios podían considerar como propio y prometedor.

Es significativo que la mayoría de las " sociedades ", de socorro, y particularmente las nuevas, tendieran a borrar de sus estatutos el paternalismo, expulsando a los socios no obreros y a suprimir las referencias religiosas, incluso en cierta medida las rituales -lo dicen sus nombres y la preocupación por formas de gestión que vienen a ser las de una democracia directa ${ }^{62}$. La hacen posible las pequeñas dimensiones de muchas, entre 100 y 300 miembros. Sería atrevido atribuir dicha forma a una intención : es un límite para que la asociación sea operativa. La gran mayoría permanecieron independientes a pesar de algunas llamadas, esencialmente en Barcelona, de personalidales moderadas que insistían en los ahorros de gestión que supondría una organización más centralizada de las sociedades de socorro -el propósito era que una parte de ellas fuese absorbido por

58 El esquema para los tipógrafos de Madrid en MORATTO, Juan José. La cuna de un gigante. Historia de la Asociación General del Arte de Imprimir, Madrid, 1925, p. 40.

59 Cf.: RALLE, M. «Protección mutualista e identidad obrera » En : CASTILLO, S. Solidaridad desde abajo..., p. 429-430.

60 Para la situación francesa, Cf. : GIBAUD, B. De la mutualité à la sécurité sociale. Conflits et convergences. Paris: Editions ouvrières, 1986, p. 44-53.

61 Las iniciativas son llamadas Caixas dels morts por obreros de fábricas catalanas ya que los dueños intentaban atraer a los obreros incluyendo en el socorro el pago de los funerales. Hay testimonios en El Productor, $17-\mathrm{VIII}-1888$ y $19-\mathrm{X}-1890$.

62 Incluso cuando llevan nombres de santos . «Toda idea política o religiosa queda rechazada » afirma el articúlo primero del Montepío de San Miguel Arcangel de San Martí de Provensals (Archivo del gobierno civil de Barcelona, legajo n. ${ }^{\circ} 830$ ) 
las redes caritativas que intentaban actuar en los medios obreros ${ }^{63}$. En todo caso las modalidades de las « asambleas » implicaban la igualdad de los socios incluso en el acceso a los cargos cuya necesaria rotatividad subrayaban los estatutos. Incluso si bastantes dificultades concretas impedían que el funcionamento fuese tan ideal -el analfabetismo era un obstáculo frecuente- el que la iniciativa aparentemente modesta del socorro asumiera ese tipo de modelo proporciona otro indicio de tal exigencia en los sectores populares.

De las tres o cuatro mil sociedades de socorro mutuo que se constituyeron entre 1880 y 1910 -antes de la primera fecha, salvo en Cataluña, eran pocas e la primera fecha - se han conservado varios centenares de folletos de estatutos. El que se materializaran bajo una forma impresa puede ser una primera señal de lo que llegaron a representar para su público. Estatutos o preámbulos reproducen, en algunas líneas, la temática ya señalada. De hecho junto con la perspectiva concreta de la función de socorro aparentemente racionalizada y descrita en un lenguaje funcional y laicizado ${ }^{64}$, evocan la capacidad infinita de la asociación de la que una caja de socorro y las cuotas que la alimentan constituyen la primera prueba. Con las funciones que se podrían añadir al socorro sería posible desembocar en la liberación social. Esta es más que implícita ya que junto con la extensión de las fuentes posibles de dinero (gracias a la venta de bebidas, a una asociación de diversión, a una cooperativa de consumo, etc.) se podrían realizar otros fines : ayuda a la invalidez, al paro, a la educación, a las diversiones, etc.. Algunos ya imaginaban que las reservas podrían servir algún día en huelgas importantes. El carácter público de los estatutos prohibía que figurase en ellos pero es bastante conocido que más tarde parte de las reservas de sociedades de socorros paralelas con secciones sindicales, en la UGT en particular, fueron utilizadas a veces para ayudar a los huelguistas del oficio ${ }^{65}$. En lo que se refiere a la ampliación ideal de las funciones los ejemplos son muy numerosos y se encuentran en los puntos más diversos del territorio español. En 1899, es decir bastante después de la ruptura representada por la FRE, en estos términos presenta sus objetivos una sociedad del municipio andaluz de la Villa de Torredonjimeno (de la andaluza provincia de Jaén) :

Su objeto es el de reunir por medio de las cuotas que se establecen un fondo con el que cooperando con las ventajas que reporten el consumo de artículos de primera necesidad y otras especies, entre los asociados, o por conciertos económicos entre los comerciantes e industriales de la población, se adquieran economías y ahorros que permitan atender los fines y propósitos de mejorar moral y materialmente a sus asociados; ofrecerles medios de instrucción y cultos recreos; socorrerles en casos de aflicción, en enfermedades o reveses de fortuna; iniciarlos en prácticas de vida sana y buenas costumbres; abrirles camino de Regeneración, despejarles horizontes de progresos, y habilitarlos a la vida de actividad y tendencias de constante mejoramiento y perfección ${ }^{66}$.

Tal mezcla de preocupaciones prácticas y de construcciones ideales suponen implícitamente que las actividades concretas, y las que estarían por venir, se dirijan hacia una solución global a la que se llegaría, por medio de las prácticas obreras

63 ALBÓ, R; MARTÍ, Cassimir. Barcelona caritativa, benéfica y social. Barcelona, 1914, 2 v., t.2, p. 271

64 La ayuda monetaria cuotidiana suele corresponder a lo que supondría pérdida de una jornada de trabajo. No está previsto que pueda durar más de un mes o dos.

65 El fenómeno es corriente en la Segunda República (Cf.: SANTOS, Juliá. Madrid, 1931-1934. De la fiesta popular a la lucha de clases. Madrid : Siglo XXI, 1984, p. 191-220).

66 Es muy significativo que en la misme fase se encuentren muchos estatutos ambiciosos en Extremadura, Andalucía, y Nueva Catilla. 
de solidaridad y de sociabilidad, de modo independiente al estado y a las iniciativas políticos, y hasta a las justificaciones de la necesidad de la revolución social. Se trata menos de proporcionar ejemplos de éxito que de mostrar la capacidad de responder a los aspectos problemáticos tanto de la actividad de trabajo de un obrero como, también, de su vida en sociedad. La perspectiva no había conocido variaciones a pesar de las muchas novedades políticas que habían intervenido después de la caida de Isabel II. Ya antes, en 1866, había escrito un periódico obrero catalán, El Obrero :

[... ] estaremos seguro de encontrar siempre amigos que nos recibirán en su seno como individuos de una misme sociedad (= asociación, M. R.) que tiene por objeto prestarnos amparos y protección en todos los momentos de la vida. / Establecida [... ] la sociedad puede constituirse a la vez en caja de crédito mutuo sobre el trabajo, en banco de previsión por las enfermedades e inutilidad, estableciendo una mutua relación entre todas las secciones de la misma. / Los proyectos de consumo y producción formarían también en lugar preferente y serán de inmediata aplicación una vez que son el principal elemento que ha de contribuir como intermediario a dar seguridad a las demás obligaciones de la colectividad ${ }^{67}$.

El Obrero no había estado en contacto con las propuestas de la Internacional. Su sensibilidad era republicana federal -ya hemos visto un ejemplo de la relación con las formas menores de solidaridad. La alusión al «banco » es probablemente una reminiscencia de la "Banque du peuple » de Proudhon. Es significativo que la tonalidad sea muy parecida en una reproducción por el periódico anarquista $L a$ Revista Social, y esto en 1881 , de un llamamiento de Alcoy a asociarse para beneficiar de una ayuda mútiple y de una perspectiva global ${ }^{68}$. La relativa permanencia del proyecto asociativo para evocar de modo algo concreto el cambio social esperado, en temas y términos tan parecidos es significativo de la presencia difusa de la cultura obrera en la que el presente artículo quiere insistir. Se ha mantenido a pesar de los grandes cambios políticos por los que ya había pasado el movimiento obrero. Sigue otorgando un papel decisivo al espacio asociativo concebido como una construcción fuera del estado y de la política. Si las propuestas de los militantes anarquistas, aquellas que insisten en la necesidad de un conflicto decisivo, parecen haber despertado un consenso de orden político en los sectores asalariados de las ciudades y del campo éste no interrumpe la preocupación por mostrar el carácter determinante de la afirmación de la identidad obrera. De hecho, tanto las cajas de resistencia de la FRE como las reservas de las sociedades de socorro mútuo no llegaron a cumplir el objetivo que anunciaban. El de las primeras apareció rápidamente imposible. En cuanto a las iniciativas de socorro, los intentos de protección a inválidos, el segundo de sus propósitos sólo tuvieron resultados simbólicos -10 céntimos por día en el mejor de los casos. No hay mejor prueba del carácter esencialmente compensatorio, muchísimo más que concreto, de las iniciativas de organización o de solidaridad.

67 El Obrero, 18-III-1866.

68 "Asóciate, obrero alcoyano, que esa es tu salvación. Si no tienes instrucción en la sociedad la encontrarás; si abusan de tí, en la sociedad, si no hoy, más adelante hallarás justicia ; si te encuentras enfermo, en la sociedad tendrás socorro ; si tienes hijos, en la sociedad aprenderán a ser hombres ; y hasta tu esposa, quien comparte todos tus sufrimientos, debes inducirla a que se asocie con sus compañeras para que en su día goce el libre albedrío, no sea humillada y maltratada injustamente, como lo es hoy por la corrupción de nuestras degradantes costumbres. Sí, obrero alcoyano, hay que olvidar esas costumbres rancias y repugnantes; entra en el camino de la civilización, que las costumbres actuales son como un edificio viejo y demolido que va a desplomarse al peso de sus años » (La Revista Social, 04-VII-1881). 
Este tipo de propuestas no representa sólo aquella aspiración a la autonomía que asoma casi en todas partes con las primeras iniciativas de solidaridad de los colectivos obreros. Tanto Thompson como Sewell han proporcionado ejemplos de emergencias, en Inglaterra y en Francia, de tal voluntad obrera, la cual tiende a borrarse cuando muchos sectores de la clase se integran en las contiendas politicas. El segundo, en particular, cita el proyecto de « asociación de las asociaciones » visible entre los obreros parisinos de la Monarchie de Juillet ${ }^{69}$, Alimentada por el eco de las grandes ideologías obreras, por importantes conflictos sociales, por la falta de interés de los estados en tomar medidas significativas en materia de protección social y por una fase de expansión de temas ideológicos radicales, la diferenciacion social conquista espacios y hasta impide, en ciertos momentos, la progresividad del proceso de integración en la propuesta política democratizadora. Acontece cuando existe la tentación de un repliegue sobre la clase. La tiene por ejemplo, es una ocurrencia más tardía, el sindicalismo revolucionario francés. El proyecto que, en España, arranca en 1870 constituye, al fin y al cabo, un caso de "autonomía obrera" para usar el concepto -también título de un libro-, propuesto por Jacques Julliard en su análisis del sindicalismo revolucionario francés. Frente a un campo político en el que la clase conseguía difícilmente inserirse, las organizaciones obreras oponen el " ser obrero » al " hacer ", sospechoso de llevar a perder la autonomía social ${ }^{70}$. El tema tiene la ventaja de señalar el carácter problemático de la integración de un movimiento obrero nacional en el marco político en el que actua. Puede ocurrir cuando la organización asume un discurso radical. El comunismo francés, en su época de fuerte presencia sociopolítica -se llegó a hablar a su respecto de « contrasociedad »- es uno de los ejemplos más conocidos. En el caso del anarquismo español evocado aquí, ya que estarían fallando tanto el sistema político como la capacidad de integración del estado, la exaltación de lo obrero ha tenido un alto nivel afectando incluso a los « marxistas » del partido obrero. Se percibe en las contestaciones poco convencidas de José Mesa, la primera personalidad de la corriente marxista en España, a los llamamientos de Engels para que en 1873 se fundara sin tardar un partido obrero ${ }^{71}:$ « [... ] la libertad y la igualdad política no dan ni un bocado de pan ni un átomo de dignidad al obrero » (22-II1873). Casi veinte años más tarde, cuando, en la mayoría de los paises, el Primero de mayo, ratificaba un tipo de conflictividad con el estado según la cual tenía que arrancársele unos disposiciones sociales legales, incluso los socialistas del PSO, y en particular Iglesias, consideraban que no se podía esperar nada de él ya que estaba totalmente entregado a la burguesía ${ }^{72}$. Si marxistas y libertarios competían por mostrar que eran los mejores defensores de lo verdaderamente obrero es porque la cercanía con la pertenencia social constituía la mejor prueba de la radicalidad de sus principios. La necesidad que tuvieron los socialistas españoles de mostrar su inserción social no hacía fácil que se alejaran de esa temática, a no ser en ciertos territorios, como en el Pais Vasco, donde la presión sobre las autoritades formaba

69 SEWELL, W. H. Work and Revolution in France., the Language of Labour from the Old Regime to 1848, Cambridge : University Press, 1980 : «El movimiento obrero de 1848 era socialista en la medida en que imaginaba un estado construido desde abajo hasta arriba en las instituciones del trabajo [... ] los gremios eran por consiguiente las instituciones públicas a las que competía el poder de organizar el trabajo de manera asociativa » (p. 355).

70 JULLIARD, Jacques. «Introduction », Autonomie ouvrière, Paris: Gallimard-Seuil, 1988, p. 9-40.

71 Cf.: RALLE, M.« La Emancipación y el primer grupo marxista español : rupturas y permanencias » En: ELORZA, A.; RALLE, M. La formación del PSOE. Barcelona: ed. Crítica, 1989, p. 94-110.

72 En su encuentro con Sagasta, después de la manifestación del Primero de mayo de 189o, Iglesias le dice « Fijándonos en la representación efectiva que tenéis -la de la clase que explota al pueblo trabajador... », El Socialista, 9-V-1890. 
parte de las modalidades de lucha que sus compañeros habían contribuido a implantar a nivel local73. La identificacón era más fácil para los anarquistas pero también suponía asumir unos espacios, físicos y discursivos los cuales, atribuyendo radicalidad a la pertenencia social, ocultaban a veces la lógica ácrata.

\section{El antiestatismo como sustituto del enfrentamiento decisivo. Mantener la ruptura}

A medida que pasa la década de 1880 , se expresan bastante más las actitudes críticas con respecto a la construcción de una "resistencia universal". Algunas iniciativas y discursos parecen franquear los límites del modelo anterior. La insistencia en considerar la espontaneidad como primer argumento para la acción parece liberarse de restos de ambigüedad como en la resolución del Congreso amplio de Sociedades de Resistencia (18-20 marzo 1888), el cual instituye una «Federación de resistencia al capital » que proclama un " Pacto de Unión y Solidaridad » entre las secciones que la constituyen. El texto final del congreso, después de subrayar que la experiencia muestra que " no ha habido una huelga reglamentaria en las diferentes federaciones obreras de resistencia »-el que se siguiera hablando de este tema es una prueba más de que sigue teniendo todavía una presencia difusa entre las asociacions obreras-, pone fuertemente de relieve las virtudes de la espontaneidad obrera :

Esto nos lleva al reconocimiento de la existencia de una fuerza que, aplicada a la obra revolucionaria, puede ser muy aprovechable y tal vez de resultados muy eficaces, si sabemos imitar al físico que, en cuanto descubre una fuerza natural, trata de emplearla..../ Para favorecer esa fuerza necesítase de la solidaridad, pero de una solidaridad espontánea e impremeditada, no de aquella calculada y fría que sólo da una orden emanada de la comisión correspondiente, como si dijésemos de una autoridad jerárquica ${ }^{74}$.

La radicalidad de las palabras podría también interpretarse como una actitud de principio que sólo se dirige a una minoría de los sectores obreros. Parece confirmarlo el bajo número de secciones y de localidades representadas en el congreso ${ }^{75}$. La transformación de la FTRE en una "Organización Anarquista Revolucionaria » tampoco reune un apoyo social considerable, a pesar de anunciarse como un congreso -tiene lugar en Valencia a principios de 1889. La debilidad de la federación había ido creciendo desde la represión del gobierno cuando éste había usado, en 1883, el pretexto de que albergaba una sociedad secreta, la « Mano Negra ». Lo que tuvo lugar fue más bien un intento de dar visibilidad a unos grupos y círculos anarquistas al presentarlos como la continuación lógica de la primera version de las organizaciones nacionales de defensa de 1870 y de 1881 . Como lo decía el anarquista que, con los argumentos habituales, describía, en el artículo ya citado, la reunión de Valencia, desaparecía la defensa y llegaba el espíritu revolucionario :

73 Un análisis global en FUSI, J. P. Política obrera en el País Vasco (1880-1923), Madrid: ed. Turner. Para las huelgas de mineros de principios de los años 1890, cf.: RALLE, M. " i Divergencias socialistas ? Madrid y Bilbao ante el conflicto minero de 1891 ».En: RALLE, M.; ELORZA, A. La formación..., p. 186-240.

74 Acracia, 06/1888, p. 622. Edición facsímil, Barcelona: Leteradura, 1978.

75 Lista en El Productor del 25-V-1888. Son unas treinta secciones de oficios, prácticamente todas de Bareclona. 
Desapareciendo la organización por secciones de oficios, la Anarquía habrá perdido aparentemente, en hombres, pero no así en la calidad de ellos, pues si bien ser1an más pocos, a lo menos estos pocos serán conscientes anarquistas, serán verdaderos anarquistas. ¿ Y qué mejor modo de aunarse estos pocos pero verdaderos y conscientes anarquistas que organizándose en grupos autónomos, libres, esto es anarquistas, relacionándose entre sí, para mejor encauzar la propaganda?

En el final de la década el resurgir de un espíritu ofensivo entre quienes se sienten anarquistas no significa, sin embargo, un cambio en las actitudes de la corriente antiautoritaria en la cual actúan. Es modesto, por ejemplo, el interés de El Productor, el cual ha adquirido desde su inicio en 1887 el estatuto de órgano principal de los sectores obreros anarquizantes -antes lo habían sido La Revista Social (1881-1884) y Bandera Social (1885-1886). Después de dedicar algunos ecos a la nueva organización deja prácticamente de citarla. Además no se modifica su actitud en lo que se refiere a la acción ni emerge la perspectiva de presentar las huelgas que llaman la atención como el primer paso de un conflicto decisivo. Tampoco se alude más claramente a las capacidades de la huelga general. En esta última parte sólo se van a dar unos ejemplos puntuales de ello porque siguen mostrando la permanencia del peso de la prioridad de la identidad obrera en los conflictos reivindicativos corrientes. En ese contexto ¿ cómo mostrar la necesaria separación política sin acciones de defensa que proporcionen ocasiones de recordar la perspectiva del conflicto decisivo?

Sólo con ocasión de algunas huelgas concretas parecen la sensibilidad anarquizante y el antiautoritarismo encontrar materia. Para El Productor son vías hacia la ruptura. Siendo la mayoría de los conflictos breves, poco densos, profesionalmente delimitados -en general por un oficio en una localidad-, y guiados por las clásicas reivindicaciones sobre el salario, las horas de trabajo o el « autoritarismo » de los maestros son pocos los que dan lugar a ese tipo de interpretaciones ${ }^{76}$. Los periódicos libertarios guardaban silencio o pronunciaban unas críticas tibias cuando los huelguistas se dirigían al gobierno civil o a alguna otra autoridad. El gran movimiento de solidaridad provocado por el conflicto textil de Manresa de 1890 no llevó a imaginar otro tipo de negociaciones. De hecho la federación del textil, las Tres Clases, controló la huelga en la que intervinirieron las autoridades y algunos políticos. El Productor la comentó poco a pesar de su dimensión excepcional.

La huelga de los albañiles de Barcelona de diciembre de 1887 ofrece uno de los pocos ejemplos de los intentos de introducir un tema rupturista a través de un conflicto social. El Productor vio en ella la posibilidad de llamar a una gestión solidaria del oficio. Habían emprendido la acción los que trabajaban en las obras de la Exposición Universal prevista para el año siguiente. Pedían una reducción de la jornada (nueve horas) a la que añadían, tal vez lo pidiera sólo un sector de la profesión, que el trabajo disponible después de la rebaja de las horas fuera repartido entre todos los del oficio, suprimiendo las situaciones de paro. No era une reivindicación inédita. Obtenerla podía dar la posibilidad de plantear que la sociedad del oficio fuera la que tuviera en adelante el monopolio de la colocación, beneficiando, por supuesto, a sus afiliados -ese control ya había sido, y lo sería más tarde, motivo de conflictos ${ }^{77}$. Demostraría la posibilidad de vincular la modalidad

76 La conocida y visible huelga de los tipógrafos de Madrid (febrero marzo de 1882), primer gran conflicto en el que participó la sensibilidad socialista, no presentó novedad en las reivindicaciones ni en la marcha del conflicto.

77 Sobre la rivalidad en este campo de las organizaciones sindicales del Madrid de la II República, consúltese el análisis fundamental de SANTOS, Juliá. De la fiesta popular a la lucha de clases, Madrid: Siglo XXI, 1984, p. 221-265. 
de defensa con el proyecto a largo plazo. Cualquiera que fuera el papel de esa reivindicación en la huelga de los albañiles, El Productor consideró ejemplar que la solidaridad sustituyera las reivindicaciones habituales:

[...] los trabajadores han adquirido la certidumbre de que, tanto si existe el previo compromiso por medio de la organización, como si tal compromiso no existe, la solidaridad obrera se establece rápida y eficazmente, y sobre esta base pueden fundarse grandes esperanzas. / Aquellas masas de hombres que [...] resisten a la tentación de exigir aumento de salario [...] demuestran que los trabajadores han comprendido la acracia y se hallan en actitud de practicarla ${ }^{78}$.

A su huelga se le atribuía más de lo que decían los albañiles. Para El Productor está claro que no introduce sólo una distancia con respecto a las reivindicaciones más corrientes sino que instala, en cierta medida, en el presente las relaciones sociales del futuro. Pero, para el periódico, lo esencial era que la intervención de las autoridades deseosas de favorecer un entendimiento entre patronos y obreros en un momento de gran necesidad -la fecha de la Exposición universalpermitía recordar lo que habían de ser las relaciones de los trabajadores con sus interlocutores :

Muéstrese la autoridad gubernativa completamente neutral, no se ocupe para nada de las huelgas provocadas por los obreros como no se ocupa por las decididas por los patronos cuando por una y otra causa cierran sus fábricas o talleres, y verá cómo aquellas siguen su curso natural, sin transgresiones de la ley, a pesar de estar hecha ésta en favor de los que poseen y de los desposeídos ${ }^{79}$.

La expresión " curso natural ", además de indicar, una vez más, que el conflicto sólo puede enfrentar a obreros y patronos, remite a una visión muy fija del modelo de conflicto. El carácter en parte irreal de la propuesta - ¿ cómo podría existir una huelga pura dentro de la legalidad ?- es significativo de la dificultad de la sensibilidad libertaria para proponer entonces acciones más ambiciosas como lo sería la huelga general. En su ausencia sólo tienen sentido las que rechacen cualquier contacto con lo que no forma parte de la experiencia propiamente obrera. Los patronos, en cambio, forman parte de ella y son erigidos, de manera formal, en interlocutores únicos. No se trataba tanto de ampliar las huelgas reales como de poner entre paréntesis, al menos de modo simbólico, lo que significaba la presencia de los aparatos estatales y políticos. Para ello el objetivo de un espacio obrero estricto era el único posible.

\section{Primero de mayo. Unas huelgas generales particular}

Las primeras celebraciones del Primero de mayo proporcionan, por consiguiente, a la corriente libertaria la oportunidad de llamar a la huelga general. Aparecía indispensable constituir una perspectiva propia y visible frente al modelo de « fiesta del trabajo » de la corriente marxista : un día de paro y de manifestaciones dirigidas a reclamar a los poderes públicos medidas legislativas sobre la jornada de trabajo. En 1890, la participación masiva, hasta en Barcelona, de los colectivos obreros en la iniciativa socialista hacía necesario distinguirse

78 El Productor, (06/08/1888).

79 El Productor, (19/08/1887). 
tanto en el objetivo como en la forma del conflicto. La desconfianza expresada por los mismos socialistas con respecto a las autoridades -otra señal colateral de la fuerte presencia de actitudes antiestatistas en los colectivos obreros españolesllamaba a actuar de modo radical ${ }^{80}$. Sin embargo, llamar a la huelga general no significaba siempre, al menos en la fase evocada aquí, un corte nítido con los temas y las iniciativas con las que el antiautoritarismo señalaba la prioridad de la afirmación de la identidad obrera. 1890. En vísperas del primer Primero de mayo, el 30 de abril, y cuando no se esperaba todavía una gran respuesta a la convocatoria socialista, un manifiesto distribuido en Madrid y presentado como anarquista, pero probablemente representativo del antiautoritarismo, indicaba que no se preveía una acción inmediata :

Y habiendo sido siempre nuestro ideal la organización del proletariado como clase social, frente a frente de las clases privilegiadas, estamos conformes con la manifestación del $1^{\circ}$ de Mayo, porque de ella ha de nacer el deseo, que se convertirá en hecho en breve plazo, de una huelga europea que supone previamente la organización de la clase trabajadora en sentido verdaderamente revolucionario ${ }^{81}$.

El espacio social que dijese la identidad revolucionaria de los «trabajadores » seguía siendo el de la actividad de una organización que había de tener una existencia «previa ». Ampliada a una « huelga europea », interfería otra vez la lógica de su constitución en la perspectiva, aparentemente nueva, de un conflicto que llegaría a ser total.

La indecisión permaneció en los primeros años de manifestaciones de Primero de mayo. En Barcelona, en 1890, después de la exitosa manifestación de los socialistas, los libertarios, habían tratado de llamar explícitamente a la huelga general de manera repentina e informal. La paralización de los tranvías o el cierre de bastantes fábricas se debieron más a disturbios callejeros provocados por algunos grupo que a extensiones de unas huelgas puntuales en algunas fábricas. El mando militar, haciéndose cargo del orden, puso fin al episodio. Sorprende más lo que pasó en Valencia, único lugar donde hubo llamamiento a la huelga general antes del día $1^{\circ}$. La preparación del movimiento se dio unas apariencias estructuradas pero su desenlace decepcionante mostró la dificultad de llevarlo a cabo y las contradicciones en las que se encontraron los organizadores. La hora de una huelga general anarquizante pareció llegar con el siguiente Primero de mayo, el de 1891. Para que el objetivo quedase claro, se intentó dar la prueba de su representatividad convocando a las asociaciones de defensa a un congreso, el conocido "Congreso Amplio ", que lo ratificara —el riesgo de subordinar la acción a las iniciativas de éstas cuando llegase el momento de actuar no se consideró como contradictorio con el espíritu de un movimiento decisivo. No tuvo un mayor impacto que la huelga de Valencia del año anterior. Por su ambición al menos aparente -la de confirmar en el terreno de los movimientos sociales la huelga general como modalidad de acción nueva y asumiendo una tonalidad anarquista-, las dos iniciativas merecen ser evocadas de manera un poco más precisa.

Son los núcleos anarquistas de Valencia, influyentes en muchas asociaciones de defensa de la ciudad, quienes dirigen, en la ciudad, el movimiento de 1890 cuyos participantes lo designan claramente como " huelga general ». Acompañadas de todo un aparato de actividades las huelgas concretas muestran el deseo de

80 RALLE, M. «Las huelgas antes y después del Primero de mayo »... , p, 73-79.

81 El Resumen, Madrid, 30/04/1890. 
añadir espectacularidad a la radicalidad del objetivo al que el papel central de las asociaciones de oficios dan una figura aparentemente contradictoria. La autonomía habitual de cada una en la toma de decisión, la atención prioritaria a las condiciones de trabajo (duración de la jornada y también salarios) ya introducen distancia entre el objetivo considerado como común y la posibilidad de que cada especialidad defina el suyo. Existe sin embargo una gran preocupación por mostrar una voluntad compartida, reuniéndose cada día los representantes de todas las asociaciones implicadas para hacer un balance de una acción que dura varios días. La favorece probablemente la convicción de que bastarían unos éxitos para que el ejemplo fuese seguido por todo el país y - ¿ quién sabe ?- más allá. Es notable el cuidado puesto en los desfiles, pacíficos, y en la escenificación, en particular el círculo dibujado en el ruedo de la Plaza de toros, donde tiene lugar el primer meeting. Esta forma geométrica permite que las asociaciones que la componen, con sus representantes y sus banderas, a veces las antiguas de los gremios, aparezcan tan iguales entre sí como los puntos que hacen existir un círculo ${ }^{82}$.

Es fuerte la preocupación por no salir del espacio social propio -y una confirmación de que la identidad obrera podía ser una manera de compensar las insuficiencias del movimiento real. Es implícita en muchas palabras. Una octavilla pide que « [...] los mismos huelguistas cuiden de que no se mezcle en ningún grupo persona extraña al respectivo arte u oficio ${ }^{83}$ ». Emergen también unas frases paradójicas y parecidas a las de El Productor cuando defendía el « curso natural » de la huelga de albañiles. Se pronuncian cuando los animadores del movimiento discuten con el gobernador civil -el aparato del gobierno Sagasta, bajo la amenaza de ser sustituido por un gabinete Cánovas, se muestra globalmente tolerante y hasta cortés con los participantes del primer Primero de mayo. Se aprovechan de la buena relación para pedir que no se transmita a Madrid su reivindicación de una jornada de ocho horas:

El señor López [militante anarquista, M. R] manifestó al señor gobernador que no procedía elevar su petición al gobierno, pues siendo anarquistas los manifestantes, nada quieren de los poderes públicos: se dirigen, no más, a los patronos para lograr sus pretensiones, encaminadas a la completa emancipación de la clase trabajadora ${ }^{84}$.

De la misma manera que para la huelga de albañiles de Barcelona, en 1887, se intenta el reconocimiento del derecho a un contacto directo entre patronos y obreros, sin intromisión del Estado ni de las fuerzas políticas constituya una salida del conflicto. Ello no impedía que se entregara al gobernador civil un documento en este sentido:

Los obreros de Valencia y, en su nombre y representación, la comisión general huelguista, compuesta de un delegado de cada una de las comisiones de oficios, significa a VS. su más solemne protesta de adhesión a la paz y tranquilidad del género humano y sus más fervientes votos para que, a fin de que cuanto antes concluya el estado actual de cosas, se capaciten los patronos de su noble y enérgica actitud, y accediendo a sus justas peticiones, no pretendan poner obstáculos al progreso, ya que es inevitable su majestuosa marcha, único medio por el que puede evitarse el perjuicio general con la resolución del problema social que en la actualidad nos ocupa. / Viva la fraternidad universal / Vivan nuestros hermanos de todo el mundo ${ }^{85}$.

82 El Mercantil Valenciano, Las Provincias. Valencia, 04/05/1890).

83 Ibidem.

84 Ibidem.

85 Ibidem. 
El objetivo era tan simbólico como modesto. Las iniciativas de Valencia reflejan en parte una historia particular, con una fuerte experiencia asociativa entre los actores están, por supuesto, los « velluters » del Arte mayor de la seda, en decadencia relativa en 1890. El socorro mutuo es el más denso después del de Cataluña ${ }^{86}$ y constituye un terreno disputado en los enfrentamientos políticos locales -en ellos interviene el republicano federal Blasco lbáñez ${ }^{87}$. La huelga general acaba en huelgas de oficios, con algunos éxitos parciales pero, también, con una dispersión de la acción. El proyecto global se va reduciendo a la afirmación de una identidad puramente obrera. Con pocas expectativas, a pesar de su capacidad de movilización, los libertarios valencianos podían encontrar una compensación en las apariencias simbólicas de ruptura. Al reivindicar que se respetase una identidad obrera estricta, con un conflicto que se reducía a un enfrentamiento entre obreros y patronos, no salían de la lógica de ésta tal como se había asumido desde la FRE.

La ambigüedad tampoco se interrumpió cuando en 1891, con ocasión del segundo Primero de mayo, las sensibilidades libertarias y antiautoritarias parecían estar de acuerdo para intentar ocupar todo el espacio español de la movilización. No era tan fácil justificar un combate decisivo en la medida en que se luchaba por la jornada de ocho horas, objetivo ideal pero fuera de alcance y condicionado por un movimiento internacional que recurría a la interpelación del estado. Por lo menos se proclamaba la voluntad de entrar en un conflicto largo. Anunciada la huelga desde principios de 1891, se la iba calificando cada vez más de " general » a medida que se iba acercando el primer día de mayo, en particular en El Productor. La equivalencia " ocho horas / huelga general » podía parecer convincente a los colectivos obreros masculinos de los oficios que habían entrado en acciones por las nueve horas -no se pedían las ocho horas para las mujeres de la industria textil ${ }^{88}$. La modalidad capaz de dar más legitimidad a la iniciativa, es decir la reunión de un « Congreso amplio » de sociedades de defensa, reproducía la combinación de las dos referencias de la huelga general de Valencia del año anterior. No borraba la ambigüedad del objetivo, el cual no generó prácticamente ningún movimiento real ya que el reconocimiento de una identidad prioritariamente social seguía dando lugar a dos interpretaciones. Desde el principio del movimiento existían por consiguiente dos salidas. La de aquellas organizaciones, en general de obreros de oficios, con suficientes fuerzas para sacar algo de una negociación con los patronos y la de un movimiento más global, el cual no llegó a constituirse. La acción « impremeditada » soñada por los libertarios en 1888 no podía, por consiguiente, alejarse mucho de la defensa prioritaria de una identidad obrera, de la que la de los sectores de oficios no estaba lejos, en la medida en que su imagen política la conseguían también manifestándose, igual que la FRE, como una expresión casi pura de la clase. En aquellos años es variable el uso de « huelga general ». Es a veces el caso de los participantes de conflictos duro para subrayar su fuerte voluntad de seguir ${ }^{89}$. Pasa en la huelga de Manresa de abril 1890. Significaba una presión suplementaria y no un cambio del modelo de acción. Ocurre más o menos

86 En Valencia el pensamiento liberal se había mostrado activo en la defensa de formas -las clásicas- de asociación. Es conocida la defensa de las hermandades por PUJOL, Eduardo Pérez. La cuestión social en Valencia, Valencia: Imprenta José Doménech, 1872.

87 En lo que se refiere a la preocupación de Blasco lbañez por controlar ciertas sociedades obreras de Valencia, véase REIG, Ramir. Obrers i ciutadans. Blasquisme i moviment obrer. València: I. Alfons el Magnànim, 1982, p.249-254.

88 A propósito de los excepcionales meetings de mujeres de abril de 1891, El Productor subraya que las oradoras apoyaban las ocho horas para sus maridos (30/04/1891).

89 «Huelga general» según Sagués de las Tres Clases (El Diluvio, La Publicidad, de Barcelona, 30-03-1890); «paro general» en El Obrero (Barcelona), semanario de las Tres Clases, 04-04-1890 
lo mismo en Vizcaya donde los mineros, conducidos por militantes socialistas ${ }^{90}$, trataban de conseguir, frente a patronos que no querían negociar directamente con los representantes de los huelguistas, una intervención de las autoridades, en particulares las militares llamadas para impedir que los desórdenes se extendiesen. La presencia de tropas significaba, además de un reconocimiento de hecho de la representatividad de los delegados, una presión sobre la patronal para que satisficiese una parte de las reivindicaciones de los huelguistas ${ }^{91}$.

\section{Principios del siglo XX. El tema de la huelga general}

En los dos momentos distintos que se acaban de evocar, las iniciativas basadas en la movilización de las organizaciones obreras se expresaron en términos parecidos. Son también significativos de la interferencia de la temática de la defensa de la identad obrera en los proyectos de cambio revolucionario. Continuaba la reticencia ya señalada con respecto a la ambición más global de las temáticas estrictamente libertarias -es significativo que éstas estuvieran más presentes en los paises donde el anarquismo tenía poco impacto entre los sectores obreros. Incluso cuando, después del cambio de siglo, la vertiente ideológico del anarquismo español empieza a ser más aparente se mantiene de hecho la prioridad otorgada a lo sindical. No es el lugar aquí de preguntarse sobre el impacto de esas elaboraciones iniciales en las bien conocidas divergencias ulteriores de la corriente libertaria dentro de la CNT (Confederación nacional del trabajo constituida en $1911^{92}$ ). Fueron muy visibles tanto en los años anteriores al golpe de estado de Primo de Rivera (1920-1923) como cuando tuvo lugar al enfrentamiento entre FAI (Federación anarquista ibérica) y « treintismo » en los años de la República. Pero la intención de estas últimas y breves páginas es dar una muestra de la efectividad de la tensión durante lo que suele considerarse como un nuevo momento, a principios del siglo XX, del anarquismo español y también de la conflictividad social.

El primer elemento de cambio es sin duda la densidad de los conflictos. El aumento alcanza a la vez el número de las huelgas y la diversidad de los huelguistas -entre los que se encuentran en 1902 y 1903, con números inéditos, los obreros agrícolas del sur93. Algunas se presentan como " generales ». La más visible es la « huelga general » de Barcelona de enero y febrero de 1902 -ya a principios 1901, en Gijón, otra « huelga general » había reunido durante largas semanas a muchos oficios y a trabajadores del puerto. También en La Coruña había tenido lugar un extenso conflicto. El de Barcelona empieza con un paro de obreros " metalúrgicos », particularmente los cerrajeros, que piden la jornada de nueve horas. La reivindicación y la solidaridad con los huelguistas se extienden más allá de las fronteras, habitualmente bien establecidas, de los oficios. Unas actitudes de

90 Ya, en 1892, la prensa local oye entre otros gritos ( « Mueran los burgueses ! », « ; Viva la revolución social ! ») alusiones a la huelga general (El Noticiero Bilbaino, 30-I-1892).

91 En el caso del gran conflicto que los socialistas quisieron en vano hacer ejemplar -la huelga des las fábricas Larios en Málaga (abril de 1894) -, no se evocó la posibilidad de llamar a una huelga general.

92 Era la continuación de la organización catalana Solidaritad obrera cuyo manifiesto inaugural salió, el 25-VII1907.

93 En una sesión del parlamento en la que se debate de la huelga de Barecelona, el presidente del consejo, Sagasta admite para los once primeros meses de su ministerio (hasta principios de febrero de 1902) un número de 600 huelgas. El movimiento se acentua en lo que queda de año (Diario de Sesiones de Cortes, sesión del 18-II-1902). Como término de comparación, en el año 1890, excepcional con respecto a los anteriores y a los pôsteriores, el número de huelgas hubiera sido de 267 (Cf.: RALLE, M. « Las huelgas antes y después del Primero de Mayo (Los conflictos españoles entre 1886 y 1864 : la irrupción del Primero de Mayo », Estudios de Historia Social. Madrid. n. 54-55, año 1991, p. 68) 
apariencia violenta llevan a las autoridades a declarar el estado de sitio. El motivo de su iniciativa era también político : la huelga ponía en duda la capacidad del régimen para asegurar el orden público tal como la proclamaba desde su proceso de establecimiento a partir el golpe de estado contra la República del general Pavía en enero de 1874. Recurrir más frecuentemente a medidas de suspensión de las garantías constitucionales era una manera de afirmar que el régimen ni se dejaba intimidar ni cambiaba94. Podían ser drásticas : la prensa de Barcelona se quedó más de una semana sin poder salir.

La mayor movilización social de principios de siglo se suele explicar por los cambios económicos, los de la " segunda » revolución industrial, y las iniciativas fiscales de un estado que tenía que racionalizar sus gastos después de la reciénte guerra de Cuba. Pero también bastantes variantes de orden político prolongaban la dinámica de crisis acentuada por la derrota y susceptible de alimentar los discursos anarquistas, los cuales también encontraban justificaciones en las iniciativas de la corriente en otros paises -ya se mencionó el impacto del sindicalismo revolucionario francés. una serie de situaciones políticas que suscitaron reacciones propiamente.

Tenía varias fuentes políticas el deseo de presencia de los núcleos anarquistas. La tensión ya la alimentaban las actitudes de la referencia conservadora cuya visión patrimonializada del estado seguía intacta. Venía evocando incluso la vía de un mayor autoritarismo cuyos temas se precisan entre el Gobierno Silvela de 1899 y la propuesta de "Revolución desde arriba » de Antonio Maura después de su primer gobierno (1903-1904). Esa perspectiva autoritaria suscitaba, por supuesto, reacciones de los núcleos anarquistas los cuales también la podían ver en las propuestas nuevas y a veces contradictorias del "regeneracionismo »-Joaquín Costa llegó a desear la venida de un « cirujano de hierro ». Las nuevas formas de movilización política republicana incitaban, ellas también, a constituir una respuesta de tono revolucionario. Con las iniciativas de Lerroux en Barcelona se difundía un tipo de presencia popular - también se manifestaba en otras ciudades como en Valencia Blasco Ibañez ${ }^{95}$. Con un lenguaje ambiguo, pero radical, justificaba que se intentara integrar si no parte de los medio populares al menos sectores de las clases medias que se contentarían con excesos verbales. Aunque no consigue un éxito electoral el intento de Costa de entrar en el campo político con la « Unión de productores » y las llamadas « clases neutras » también refuerza los enfoques radicales por su insistencia en denunciar las estructuras de poder tradicional-hace del « caciquismo » un tema político central96. Los enfrentamientos sobre lo que se veía como " autoridades » eran un motivo de intervención para la militancia anarquista ya que podía usar contra ellos las temáticas de descalificación de las querencias autoritaristas. Hasta entonces el componente anarquista más ideológico había encontrado las dificultades ya evocadas para hacerse más visible. Pero ahora podía creer en la posibilidad de llevar a la base social obrera a asumir el enfrentamiento decisivo y global que las distintas variantes del anarquismo consideraban como central. Son significativas de una nueva capacidad de movilización las publicaciones que desarrollan el tema de la huelga general, El Productor (su segunda época ») y La Huelga General97. Como es sabido, Francisco

94 CALLEJA, Eduardo González. La razón de la fuerza, Madrid: CSIC, 1998 , p. 19-73.

95 Cf.: CULLA I CLARÀ, J. B. El republicanisme lerrouxista a Catalunya (1901-1923). Barcelona: Curial, 1986 y JUNCO, J. Álvarez. El emperador del Paralelo. Madrid: Alianza, 1990. Para la actividad de Blasco Ibánez, cf.: REIG, R. Blasquistas y clericales. Valencia: Institució Alfons el Magnamim, 1986.

96 Un análisis articulado del pensamiento de J. Costa en MAURICE, Jacques; SERRANO, Carlos. Joaquín Costa: crisis de la Restauración y populismo. Madrid: Siglo XXI, 1977.

97 El primer número de la segunda época de El Productor sale en Barcelona el 6-VII-1901, el de La Huelga 
Ferrer apoya y, en gran medida, orienta el segundo periódico, haciéndose eco del debate que tiene lugar a nivel internacional precisamente sobre la huelga general y reproduciendo bastante de lo que escriben los órganos del llamado « sindicalismo revolucionario " francés $^{98}$.

Detrás de la nueva visibilidad que, con ocasión de la huelga general, adquiría en Barcelona el conjunto al que pertenecía un sindicalismo con recuerdos antiautoritarios y los círculos libertario más ideológicos ${ }^{99}$, subsistían sin embargo las tensiones. Indudablemente hay más energía en la lucha de los huelguistas y asumen objetivos más ambiciosos, pero éstos se siguen expresando en términos reivindicativos incluso si insisten más en el papel de una amplia solidaridad que deja de obedecer a las pautas formales de antes. Así lo dice un manifiesto de los « metalúrgicos » en huelga :

Compañeros, [...] seguid en la lucha emprendida hasta conseguir que los patronos metalúrgicos abran los talleres a sus obreros con la jornada de 9 horas; seguid prestando vuestro simpático apoyo a una causa tan justa y haréis que la dignidad obrera quede respetada y apreciada de todo el universo. Un esfuerzo más y la victoria es nuestra. .... Adelante, pues, que al lado de nuestra causa que es la de ellos, están nuestros hermanos de Sabadell, Tarrasa, Manresa y otros que no tardarán en secundarnos en la lucha por la razón y la justicia. / ¡Trabajadores todos: unión y solidaridad! ¡Viva la huelga general'100!

En este texto la « dignidad obrera », a pesar de mostrar su capacidad para dar un alcance « universal » al conflicto, tiene el mismo carácter central que la defensa prioritaria de la identidad obrera de los años 1870 y 1880 . En cambio no aceptan ni un objetivo que consideran como reducido -el de la jornada de trabajoni el recurso al sintagma « huelga general » quienes, más claramente anarquistas, interpretan, en órganos militantes relativamente leidos, la huelga de los obreros metalúrgicos como el inicio de aquel enfrentamiento decisivo que llevaría más lejos. El que los huelguistas Ilamaran « general » su conflicto porque implicaba todos los oficios del ramo y porque había suscitado la solidaridad de otros oficios frente a la reacción severa de las autoridades no significaba que habían salido de una huelga esencialmente económica -no llegaban a decir de objetivo únicamente obrero $^{101}$. Era preciso darle otro contenido y hasta usar otras palabras ya que según La Huelga General en pleno conflicto de los metalúrgicos de Barcelona : « [...] muchos huelguistas van a la huelga como los republicanos a los banquetes del 11 de febrero. [...] No podrán, recurriendo a ella pacíficamente, emanciparse del salario, su mayor yugo opresor ${ }^{102}$ ». Los enfrentamientos de 1902, con suspensión de las garantías constitucionales, ayudaban, de momento, a proponer que en adelante las huelgas violentas se considerasen como las únicas que pudieran beneficiar a los obreros. Reducir a resultados de orden reivindicativo las modalidades de una lucha de dimensión poco corriente es significativo tanto de la distancia que se

General, el 15-XI-1901.

98 No es el caso de PERE, Gabriel. « Sindicalismo y huelga ». En : BONAMUSA, Francesc (ed.). La Huelga general, Ayer, n. 4, 1991, Madrid: Marcial Pons, 1991, pp,33-34.

99 Cf.: CALLEJA, G. Op. cit., p. 304 y ss.

100 Citado por RIQUER, Borja de. Lliga regionalista: la burguesía catalana i el nacionalismo (1893-1904). Barcelona: Edicions 62, 1977, p. 344.

101 El uso de « huelga general » para conflictos que antes no se definían como tales se confirma en el recurso más frecuente a la fórmula. En, 1903, en las minas de Bilbao, la huelga de los mineros se define de entrada como « huelga general » (cf.: Instituto de Reformas Sociales. Informe referente a las minas de Vizcaya, Madrid, 1904). Un relato del enfrentamiento en FUSI, J. P. Op. cit., p. 230-243.

102 La Huelga General. Barcelona, 25/01/1902. 
quería introducir con las conductas consideradas sólo sociales como con la relativa permanencia de éstas. Un manifiesto anarquista distribuido en los días clave del conflicto barcelonés ya le daba como objetivo la « revolución social » :

De los que trabajan que nadie se mueva, que todos sepan matar el egoísmo de los vampiros acaudalados, soportando el carecer en silencio, el hambre para todos. [...] Por consecuencia, alto; que todos efectúen el paro del trabajo desde mañana mismo, y demostraremos a la clase directiva y capitalista que sin los obreros, a quienes desprecian, no es posible la vida social. ¡Viva la revolución social!103!

En el congreso de 1870, A. Lorenzo evocaba, en la frase ya citada, el paso de la interrupción del trabajo a la situación de impotencia de los burgueses. La visión repetida en 1902 no había perdido su carácter relativamente paradójico. Reconocía por una parte que la revolución social había de salir forzosamente, y con algo de violencia, de las iniciativas de los sectores que componen el trabajo asalariado. Se mantenía sin embargo la ambigüedad de la inserción del cambio revolucionario en un espacio social del que también se desconfiaba -el que La Huelga General del 25 de enero, atribuyera a la mayoría de los obreros la incapacidad a salir de sus costumbres es, al fin y al cabo, muy significativo. En aquel principio de un nuevo siglo la relación con lo que muchos anarquistas veían como una especificidad obrera positiva seguía siendo fuente de dificultades para definir una vía de acción.

Tal vez sorprenda que la tensión habitual entre las dos expresiones obreras que componen los movimientos obreros nacionales, la sindical y la política, afecte también una situación atípica en la que la sindical quiere rechazar las formas de la negociación en las que se inscribían casi todas sus versiones europeas. La inserción social en unos colectivos obreros solicitados para hacer evidente la ruptura que suponía introdujo una segunda referencia con una lógica propia. Al fin y al cabo empezó como algo problemático el encuentro que la corriente libertaria juzgaba indispensable.

Recebido em 01/05/2013

Aprovado em 05/06/2013

103 Citado por El Liberal.Madrid, 18/02/1902. 